\title{
Strategies for clinical development of monoclonal antibodies beyond first-in-human trials: tested doses and rationale for dose selection
}

\author{
Marie Viala ${ }^{1}$, Marie Vinches ${ }^{1}$, Marie Alexandre ${ }^{1}$, Caroline Mollevi ${ }^{1}$, Anna Durigova ${ }^{2}$, Nadia Hayaoui ${ }^{1}$, Krisztian \\ Homicsko ${ }^{3}$, Alice Cuenant ${ }^{1}$, Céline Gongora ${ }^{4}$, Luca Gianni ${ }^{5}$ and Diego Tosi ${ }^{*, 1,4}$ \\ ${ }^{1}$ Institut du Cancer de Montpellier, Montpellier, France; ${ }^{2}$ Geneva University Hospitals, Geneva, Switzerland; ${ }^{3}$ Centre Hospitalier \\ Universitaire Vaudois, Lausanne, Switzerland; Institut de Recherche en Cancérologie de Montpellier, Inserm U1194, Montpellier, \\ France and ${ }^{5}$ San Raffaele - Scientific Institute, Milan, Italy
}

Background: Our previous survey on first-in-human trials (FIHT) of monoclonal antibodies (mAbs) showed that, due to their limited toxicity, the recommended phase II dose (RP2D) was only tentatively defined.

Methods: We identified, by MEDLINE search, articles on single-agent trials of mAbs with an FIHT included in our previous survey. For each $\mathrm{mAb}$, we examined tested dose(s) and dose selection rationale in non-FIHTs (NFIHTs). We also assessed the correlation between doses tested in the registration trials (RTs) of all FDA-approved mAbs and the corresponding FIHT results.

Results: In the 37 dose-escalation NFIHTs, the RP2D indication was still poorly defined. In phase II-III NFIHTs ( $n=103$ on 37 mAlbs), the FIHT RP2D was the only dose tested for five mAbs. For 16 mAlbs, only doses different from the FIHT RP2D or the maximum administered dose (MAD) were tested and the dose selection rationale infrequently indicated. In the 60 RTs on 27 FDAapproved mAbs with available FIHT, the FIHT RP2D was tested only for two mAbs, and RT doses were much lower than the FIHT MAD.

Conclusions: The rationale beyond dose selection in phase II and III trials of mAbs is often unclear in published articles and not based on FIHT data.

The main aim of first-in-human trials (FIHTs) is to explore the safety of multiple escalating doses of a drug in order to identify the highest dose associated with a tolerable toxicity. This is usually defined as the maximum-tolerated dose (MTD) (Eisenhauer et al, 2000; Le Tourneau et al, 2009) and is frequently selected for the subsequent drug development, on the basis of the assumption that a positive correlation exists between the drug dose and its effect. It is then indicated as the recommended phase II dose (RP2D) (Le Tourneau et al, 2009). Available data convincingly showed that
FIHTs are the most important step in determining the dose of FDA-approved anticancer drugs, because for most molecules the RP2D is determined on the basis of the MTD, and the dose tested in registration trials (RTs) is within $20 \%$ on either side of the RP2D (Jardim et al, 2014). More uncertainty exists about dose selection for targeted agents, because in this case, the RP2D coincides less frequently with the MTD and predicts poorly the dose used in RTs (Jardim et al, 2014). Indeed, designing and interpreting FIHTs for targeted agents is difficult because of their limited acute toxicity

*Correspondence: Dr D Tosi; E-mail: diego.tosi@icm.unicancer.fr

Received 28 March 2017; revised 29 November 2017; accepted 30 November 2017; published online 13 February 2018

(C) 2018 Cancer Research UK. All rights reserved 0007 - 0920/18 
(the first-cycle toxicity is usually the endpoint for MTD selection), and because of the scarce correlation between pharmacokinetic (PK) or pharmacodynamic (PD) parameters and drug efficacy in this setting (Parulekar and Eisenhauer, 2004; Jardim et al, 2014; Janne et al, 2016; Sweis et al, 2016). The challenge is even greater in FIHTs of monoclonal antibodies (mAbs) due to the low risk of acute toxicity associated with these molecules as a consequence of their lack of off-target effects (Sachs et al, 2016), and also because conventional FIHTs cannot capture the medium- and long-term toxicity of tested drugs. We recently conducted a comprehensive analysis of the design, implementation and outcome of FIHTs on mAbs published between 2000 and 2013 (Tosi et al, 2015). We found that, for most of the tested molecules, early-occurring adverse events were rare and dose escalation could be continued up to the highest planned dose level in all trials. Consequently, the MTD could be identified only in a minority of trials. Conversely, the RP2D was indicated in an important proportion of FIHTs, mainly in the absence or independently of the MTD and on the basis of PK or PD considerations. The PK data used to justify the RP2D choice mostly relied on comparisons between the drug concentrations found to be effective in preclinical studies and the clinical PK findings. PD data often focused on receptor occupancy assessment. However, the correlation between PK or PD parameters in preclinical models and in patient samples is far from being clearly established, which makes RP2D recommendations based on these observations at least doubtful. Despite these uncertainties in RP2D selection, $\mathrm{mAb}$ clinical development achieved several important successes for the treatment of malignancies and immunologic disorders (Nelson et al, 2010); however, comprehensive reviews are not available on the strategies of mAb clinical testing following FIHTs.

The aim of this study was to evaluate the strategies of $\mathrm{mAb}$ clinical development by analysing single-agent non-FIHTs (NFIHTs) of mAbs the FIHT of which was included in our previous analysis (Tosi et al, 2015), as well as the RTs of all FDAapproved mAbs. After retrieving from MEDLINE all publications on these NFIHTs and RTs, we examined the trial design and results, with a particular focus on the relationship between FIHT data and doses tested in these trials.

\section{MATERIALS AND METHODS}

Article search. In June 2016 we performed a MEDLINE search to identify articles on single-agent trials of mAbs the FIHT of which was included in our previous analysis (Tosi et al, 2015). Separately, we identified mAbs approved as single agents by FDA up to 31 June 2016, and for each molecule we performed a MEDLINE search (using all the known names of each drug) to identify the FIHT and RTs. We excluded trials reporting on immunoconjugates, radioimmunoconjugates and non-systemic routes of administration (topical administration or ex-vivo treatment), trials on Asian patients performed to confirm previous results obtained in Western patients, phase III trials where the evaluated $\mathrm{mAb}$ was used as standard treatment, as well as articles not written in English language. The phase I and phase II parts of phase I/II studies were analysed separately when possible.

Data collection and analysis. From articles on the NFIHTs of $\mathrm{mAbs}$ with an FIHT included in our previous review (Tosi et al, 2015), we extracted treated disease, trial phase, rationale for dose(s) selection, administration route, dose calculation unit, schedule, presence of loading dose, tested dose(s), number of included patients, and availability of PK or PD data. From dose escalation trials, we also extracted the starting dose (SD), the maximum planned dose, the maximum administered dose (MAD), the MTD, the RP2D and the rationale for RP2D selection. For these trials, we calculated the ratio between FIHT MAD and NFIHT MAD, the ratio between NFIHT RP2D and FIHT MAD and the ratio between NFIHT RP2D and FIHT RP2D. For phase II and III trials, we calculated the ratio between the tested dose and FIHT MAD or FIHT RP2D. For the analysis of the RTs concerning mAbs approved by the FDA, we extracted treated disease, administration route, dose calculation unit, schedule, presence of loading dose, tested dose(s), number of included patients, and the three most frequent grade $3 / 4$ toxicities. From the relevant FIHT, we recorded MAD, MTD, RP2D and the three most frequent grade $3 / 4$ toxicities. We calculated the ratios between RT dose and FIHT MTD and MAD, respectively. When more than one trial was available for a given $\mathrm{mAb}$ in a data set, we used the mean of the ratios from all the trials of this $\mathrm{mAb}$ to calculate summary statistics on the dose ratios for the entire data set. We used descriptive statistics to report whether the top-three grade $3 / 4$ toxicities in the RTs of each mAb were detected in the corresponding FIHT, and their grade in the FIHT. Statistical analyses were performed with the R software (version 3.3.2).

\section{RESULTS}

General results on NFIHTs. After reviewing the 139 articles retrieved with the MEDLINE search, we selected for analysis 144 NFIHTs of $42 \mathrm{mAbs}$ (1-15 NFIHTs for each molecule). The study design and drug administration data of the selected NFIHTs are shown in Table 1 . Specifically, 39 studies (27\%) were phase I and $103(72 \%)$ phase II or III trials. Most trials concerned patients with solid cancers or haematological malignancies $(n=111,77 \%)$, while the others focused mainly on immunologic disorders. In 131 trials (91\%), the mAb was administered only by intravenous route and a loading dose was used in 20 (14\%). For most mAbs, the same dose calculation method was used in NFIHTs and the corresponding FIHT. However, in 16 NFIHTs, a flat dose was administered instead of the dose tested in the FIHT and calculated according to weight $\left(\mathrm{mg} \mathrm{kg}^{-1}\right)$ or body surface $\left(\mathrm{mg} \mathrm{m}^{-2}\right)$.

Analysis of dose escalation NFIHTs. In 37 of the 39 of phase I trials, a dose escalation procedure was implemented (for $21 \mathrm{mAbs}$ ). We found that the highest planned dose corresponded to the FIHT MAD for nine of the $19(47 \%)$ mAbs tested in the NFIHTs that used the FIHT dose calculation method. Indeed, the range of ratios

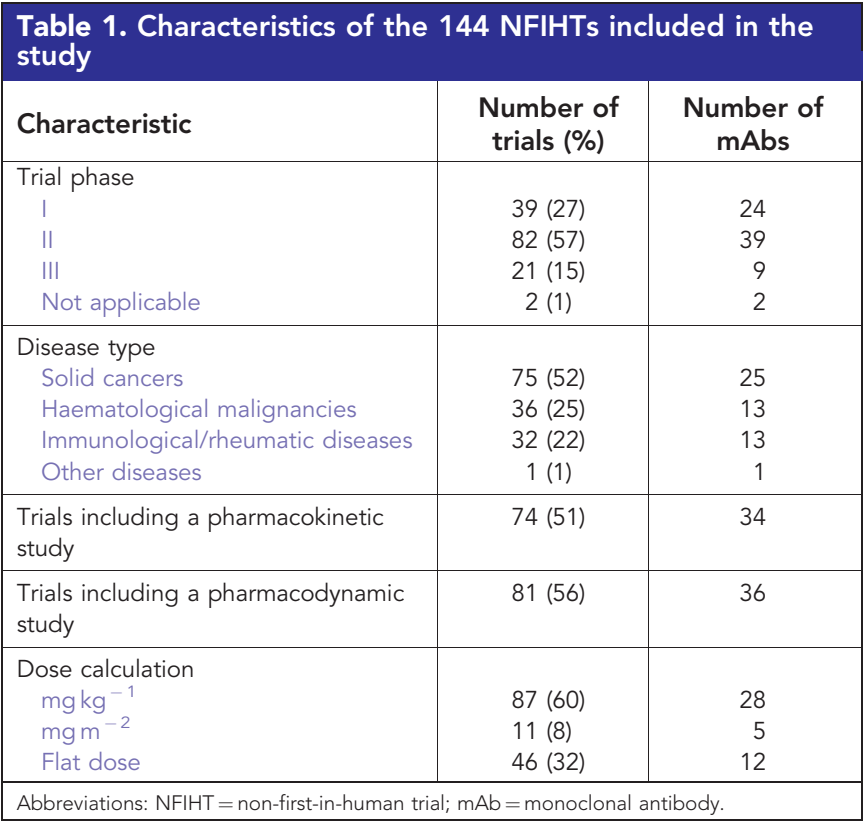


between the highest NFIHT planned dose and FIHT MAD was quite wide (0.1 to 6); however, for $15 \mathrm{mAbs}(71 \%)$ in 21 trials $(65 \%)$ the highest planned dose level was lower or equal to the FIHT MAD, and for $15 \mathrm{mAb}(71 \%)$ in 19 trials (59\%) it was within $33 \%$ on either side of the FIHT MAD (Figure 1). Like in the FIHT, in all NFIHTs the mAb favourable safety profiles allowed dose escalation up to the highest planned dose level that, therefore, coincided with the MAD. An MTD was found for only seven of 21 mAbs (33\%) tested in eighth (22\%) dose escalation trials. An RP2D was indicated for 11 of the $21 \mathrm{mAbs}(52 \%)$ tested in 15 of the 37 NFIHTs (40\%), but it matched the FIHT RP2D for only three mAbs in four trials (Figure 1). The rationale for RP2D selection was described for only $11 \mathrm{mAbs}$ (Table 2) and was based on considerations about safety $(n=6)$, PK $(n=4)$, and PD $(n=1)$. The medians of the NFIHT RP2D/FIHT RP2D and NFIHT RP2D/ FIHT MAD ratios were 2.2 (range: 1 to 6 ) and 0.65 (range: 0.3 to 1 ), respectively.

Analysis of phase II and III NFIHTs. We then analysed the doses tested in the 103 phase II and III trials (on 37 mAbs) with regard to the FIHT results to assess FIHT data relevance for the subsequent $\mathrm{mAb}$ development. First, we evaluated how the tested dose(s) was selected (Table 3). A rationale was indicated for $26 \mathrm{mAbs}(70 \%)$ in 57 of the 103 trials (55\%) and was based on the FIHT RP2D (19 trials), PK data (7 trials), efficacy (7 trials), FIHT MAD (4 trials), PD (2 trials), FIHT MTD (1 trial) or other considerations
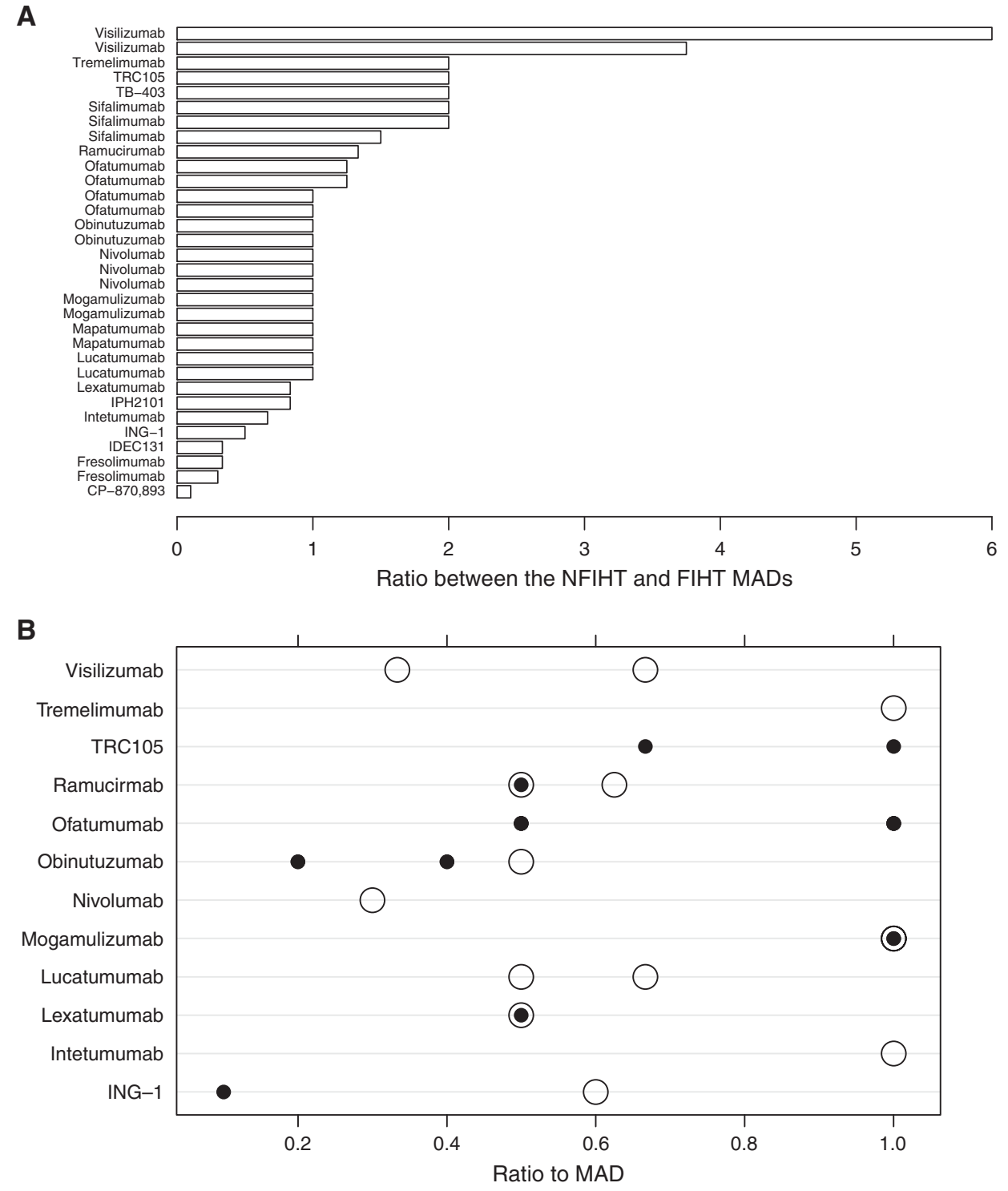

NFIHT RP2D/FIHT MAD ratio

- FIHT RP2D/FIHT MAD ratio

Figure 1. Relationship between NFIHT MAD, NFIHT RP2D and FIHT MAD for dose-escalating NFIHTs. (A) Ratio between the NFIHT MAD and the FIHT MAD for each NFIHT with dose escalation. Each bar represents the ratio between the highest planned dose of each NFIHT and the relevant FIHT. The names of tested mAb are indicated on the left. (B) Ratio between the NFIHT RP2D and the FIHT MAD for NFIHTs with dose escalation. Filled circles represent the ratio between NFIHT RP2D and FIHT MAD. Each circle refers to a dose tested in one or more NFIHTs. The names of tested $\mathrm{mAb}$ are indicated on the left. For comparison, hollow circles represent the ratio between RP2D and MAD in the corresponding FIHT. FIHT=first-in-human trial; MAD=maximum administered dose; NFIHT=non-first-in-human trial; RP2D=recommended phase II dose. 
Table 2. Rationale for RP2D selection in trials with dose escalation

\begin{tabular}{|c|c|c|c|c|c|c|c|c|c|}
\hline \multicolumn{2}{|c|}{ References } & mAb name & $\begin{array}{c}\text { Dose } \\
\text { calculation }\end{array}$ & \multicolumn{2}{|c|}{ FIHT } & \multicolumn{4}{|r|}{ NFIHT } \\
\hline $\begin{array}{l}\text { Baselga } \\
\text { et al, } 2000\end{array}$ & $\begin{array}{l}\text { Tabernero } \\
\text { et al, } 2010\end{array}$ & Cetuximab & $\mathrm{mg} \mathrm{m}^{-2}$ & & $100 \mathrm{qw}$ & $\begin{array}{l}700 \\
q 2 w\end{array}$ & & $\begin{array}{l}500 \\
q 2 w\end{array}$ & $\begin{array}{l}\text { These data indicate that the closest PK } \\
\text { match to the weekly standard regimen } \\
\text { will be provided by every-second-week } \\
\text { administration of } 500 \text { or } 600 \mathrm{mg} \mathrm{m}^{-2} \\
\text { with } 500 \mathrm{mg} \mathrm{m}^{-2} \text { being the dose of } \\
\text { choice on this schedule in terms of } \\
\text { convenience and feasibility. }\end{array}$ \\
\hline $\begin{array}{l}\text { Mullamitha } \\
\text { et al, } 2007\end{array}$ & $\begin{array}{c}\text { O'Day } \\
\text { et al, } 2011\end{array}$ & Intetumumab & $\mathrm{mg} \mathrm{kg}^{-1}$ & & $\begin{array}{c}10 \mathrm{~d} 1,29 \\
36,43\end{array}$ & $\begin{array}{c}20 \\
q 3 w\end{array}$ & & $10 q 3 w$ & $\begin{array}{l}\text { The clinical activity of the two dose } \\
\text { levels was very similar in this study with } \\
\text { the exception of the duration of grade } \\
1 \text { uveitic reaction after the first dose (7- } \\
8 \text { days in patients treated with } \\
10 \mathrm{mg} \mathrm{kg}^{-1} \text { and } 6-14 \text { days in patients } \\
\text { treated with } 20 \mathrm{mg} \mathrm{kg}^{-1} \text { ). There was } \\
\text { no sequela in any patient. Based on } \\
\text { these results, it is recommended that } \\
\text { future studies with intetumumab } \\
\text { continue to include the } 10 \mathrm{mg} \mathrm{kg}^{-1} \\
\text { dose level. }\end{array}$ \\
\hline $\begin{array}{l}\text { Plummer } \\
\text { et al, } 2007\end{array}$ & $\begin{array}{l}\text { Wakelee } \\
\text { et al, } 2010\end{array}$ & Lexatumumab & $\mathrm{mg} \mathrm{kg}^{-1}$ & $10 q^{3} w$ & $20 q 3 w$ & $\begin{array}{c}10 \\
q 2 w\end{array}$ & & $10 q 2 w$ & $\begin{array}{l}\text { Based on the previously determined } \\
\text { MTD of lexatumumab }\left(10 \mathrm{mg} \mathrm{kg}^{-1}\right. \\
\text { every } 21 \text { days), escalation beyond } \\
10 \mathrm{mg} \mathrm{kg}^{-1} \text { was not attempted. }\end{array}$ \\
\hline $\begin{array}{l}\text { Bensinger } \\
\text { et al, } 2012\end{array}$ & $\begin{array}{c}\text { Byrd et al, } \\
2007\end{array}$ & Lucatumumab & $\mathrm{mg} \mathrm{kg}^{-1}$ & & $6 \mathrm{qw}$ & $6 \mathrm{qw}$ & $3 \mathrm{qw}$ & $3 q w$ & $\begin{array}{c}\text { There was essentially } 100 \% \text { saturation } \\
\text { of CD40 molecules at the end of each } \\
\text { infusion for all dose groups, but this } \\
\text { saturation was lost prior to the } \\
\text { beginning of the next infusion in the } \\
0.3 \mathrm{mg} \mathrm{kg}^{-1} \text { and } 1.0 \mathrm{mg} \mathrm{kg}^{-1} \text { dose } \\
\text { cohorts. In the remaining three dose } \\
\text { cohorts }\left(\geqslant 3.0 \mathrm{mg} \mathrm{kg}^{-1}\right) \text {, bound } \\
\text { lucatumumab remained on circulating } \\
\text { chronic lymphocytic leukaemia cells } \\
\text { between infusions. }\end{array}$ \\
\hline $\begin{array}{l}\text { Yamamoto } \\
\text { et al, } 2010\end{array}$ & $\begin{array}{c}\text { Duvic et al, } \\
2015\end{array}$ & Mogamulizumab & $\mathrm{mg} \mathrm{kg}^{-1}$ & $1 \mathrm{qw}$ & $1 \mathrm{qw}$ & $\begin{array}{r}1 \mathrm{qw} \\
\times 4\end{array}$ & & $\begin{array}{c}1 \mathrm{qw} \\
\times 4\end{array}$ & MAD \\
\hline $\begin{array}{l}\text { Brahmer } \\
\text { et al, } 2010\end{array}$ & $\begin{array}{c}\text { Ansell } \\
\text { et al, } 2015\end{array}$ & Nivolumab & $\mathrm{mg} \mathrm{kg}^{-1}$ & & $10 q 2 w$ & $\begin{array}{l}3 \mathrm{~d} 1 \\
28 \\
\text { then } \\
\mathrm{q} 2 \mathrm{w}\end{array}$ & & $\begin{array}{l}3 \mathrm{~d} 1 \\
28 \\
\text { then } \\
\mathrm{q} 2 \mathrm{w}\end{array}$ & MAD \\
\hline $\begin{array}{l}\text { Salles et al, } \\
2012\end{array}$ & $\begin{array}{c}\text { Sehn et al, } \\
2015\end{array}$ & Obinutuzumab & $\mathrm{mg}$ & $\begin{array}{c}1600 / 800 \\
\text { and } 400 / \\
400 \mathrm{~d} 1,8, \\
21 \text { then } \\
\text { q3w }\end{array}$ & $\begin{array}{l}1200 / 2000 \\
\mathrm{~d} 1,8,21 \\
\text { then } \mathrm{q} 3 \mathrm{w}\end{array}$ & $\begin{array}{c}1200 / \\
2000 \\
\text { qw }\end{array}$ & & $\begin{array}{c}1000 / \\
1000 \\
\text { qw }\end{array}$ & $\begin{array}{l}\text { The observed plasma concentration } \\
\text { data across the cohorts indicated } \\
\text { substantially higher concentrations } 14 \\
\text { days after completion of the induction } \\
\text { phase at doses of } 1000 \mathrm{mg} \text { and } 1200 / \\
2000 \mathrm{mg} \text {, indicating target saturation. } \\
\text { Consequently, a dose of } 1000 \mathrm{mg} \text { was } \\
\text { chosen for further clinical studies. }\end{array}$ \\
\hline
\end{tabular}




\section{Table 2. (Continued)}

\begin{tabular}{|c|c|c|c|c|c|c|c|c|c|}
\hline \multicolumn{2}{|c|}{ References } & \multirow[t]{2}{*}{ mAb name } & \multirow{2}{*}{$\begin{array}{l}\text { Dose } \\
\text { calculation }\end{array}$} & \multicolumn{2}{|c|}{ FIHT } & \multicolumn{4}{|r|}{ NFIHT } \\
\hline FIHT & NFIHT & & & $R P 2 D$ & MAD & MAD & MTD & $R P 2 D$ & Rationale for RP2D selection \\
\hline $\begin{array}{l}\text { Spratlin } \\
\text { et al, } 2010\end{array}$ & $\begin{array}{l}\text { Chiorean } \\
\text { et al, } 2015\end{array}$ & Ramucirumab & $\mathrm{mg} \mathrm{kg}^{-1}$ & $8 q 2 w$ & $16 q 2 w$ & 20 & & $\begin{array}{l}8 q 2 w \\
\text { or } 10 \\
q 3 w\end{array}$ & $\begin{array}{l}\text { Doses within this range yielded the } \\
\text { minimum trough concentrations that } \\
\text { exceeded the } 20 \mu \mathrm{g} \mathrm{ml}^{-1} \text { levels } \\
\text { associated with growth inhibition in } \\
\text { preclinical human tumour xenograft } \\
\text { models and with preliminary evidence } \\
\text { of efficacy. In addition, doses of } \\
\geqslant 8 \mathrm{mg} \mathrm{kg}^{-1} \mathrm{Q} 2 \mathrm{~W} \text { were associated } \\
\text { with relatively stable clearance profiles } \\
\text { (as opposed to more dose-dependent } \\
\text { patterns seen at lower doses), } \\
\text { consistent with saturation of the target- } \\
\text { mediated clearance pathway. }\end{array}$ \\
\hline Ribas, 2005 & $\begin{array}{l}\text { Camacho } \\
\text { et al, } 2009\end{array}$ & Tremelimumab & $\mathrm{mg} \mathrm{kg}^{-1}$ & & $\begin{array}{l}15 \text { single } \\
\text { dose }\end{array}$ & $\begin{array}{c}10 \\
q 4 w\end{array}$ & & $\begin{array}{l}15 \\
\text { every } 3 \\
\text { months }\end{array}$ & $\begin{array}{c}\text { During the phase II study, } 89 \text { patients } \\
\text { received } 10 \mathrm{mg} \mathrm{kg}^{-1} \text { tremelimumab } \\
\text { once every month or } 15 \mathrm{mg} \mathrm{kg}^{-1} \text { every } \\
3 \text { months. The results of this study } \\
\text { supported the choice of the } \\
15 \mathrm{mg} \mathrm{kg}^{-1} \text { every } 3 \text { months regimen } \\
\text { for further clinical development. Within } \\
\text { the limitations of this non-comparative } \\
\text { phase II two-arm clinical trial, both } \\
\text { regimens were associated with durable } \\
\text { tumour responses, but } 15 \mathrm{mg} \mathrm{kg}^{-1} \\
\text { every } 3 \text { months was more convenient } \\
\text { to administer and was associated with } \\
\text { fewer and less severe/serious adverse } \\
\text { events. }\end{array}$ \\
\hline $\begin{array}{l}\text { Norman } \\
\text { et al, } 2000\end{array}$ & $\begin{array}{c}\text { Plevy et al, } \\
2007\end{array}$ & Visilizumab & $\mu \mathrm{g} \mathrm{kg}^{-1}$ & & 15 once & $\begin{array}{c}15 \mathrm{~d} 1 \\
\mathrm{~d} 2\end{array}$ & $\begin{array}{l}10 \\
d 1 \\
d 2\end{array}$ & $\begin{array}{l}10 \mathrm{~d} 1 \\
\mathrm{~d} 2\end{array}$ & MTD \\
\hline $\begin{array}{l}\text { Norman } \\
\text { et al, } 2000\end{array}$ & $\begin{array}{l}\text { Baumgart } \\
\text { et al, } 2010\end{array}$ & Visilizumab & $\mu \mathrm{g} \mathrm{kg}^{-1}$ & & 15 once & $\begin{array}{c}12.5 \\
d 1, d 2\end{array}$ & & $\begin{array}{c}5 \mathrm{~d} 11 \\
\mathrm{~d} 2\end{array}$ & $\begin{array}{l}\text { Chosen as the optimal clinical dose } \\
\text { because of comparable efficacy and } \\
\text { less toxicity than with higher doses. }\end{array}$ \\
\hline
\end{tabular}

(17 trials). We then examined the relationship between FIHT RP2D and doses tested in NFIHTs (Figure 2). FIHT RP2Ds (one or more for each $\mathrm{mAb}$ ) were available for 12 of the $37 \mathrm{mAbs}$ and were tested for $11 \mathrm{mAbs}$, alone $(n=5 \mathrm{mAbs})$ or in association with other doses ( $n=6 \mathrm{mAbs})$. The FIHT MAD was tested for eight mAbs (73\%) in 17 trials (45\%) of mAbs with available FIHT RP2D. The ratio between the doses tested in NFIHTs and the corresponding FIHT RP2Ds ranged from 0.1 to 5 , and in $84 \%$ of cases the tested dose/FIHT RP2D ratio was not within $33 \%$ on either side of the FIHT RP2D (Figure 2). The FIHT MAD of 17 mAbs (46\%) was tested alone or with other doses in 36 trials (35\%). Only doses different from the FIHT RP2D or MAD were tested for $16 \mathrm{mAbs}(43 \%)$ in 37 trials (36\%). Finally, we verified that the tested doses were included in the range established as safe in the FIHT and compared them with the FIHT MAD (Figure 2). Only in nine trials on two mAbs, the tested dose was higher than the FIHT MAD. The median tested dose/FIHT MAD ratio was 0.71 (range: 0.25 to 2.5 ) in trials with comparable dose calculation methods.
Analysis of the correlation of doses and toxicities in RTs and the corresponding FIHT. We retrieved 27 FDA-approved mAbs with a FIHT and 60 RTs on these molecules (Supplementary Table S1). The $\mathrm{mAb}$ indication was cancer (solid tumours for eight mAbs, haematological cancers for three mAbs), immune system diseases (13 mAbs) and other diseases (four mAbs). The FIHT MTD was available for only one molecule, whereas the FIHT RP2D was indicated for seven mAbs (26\%; five cancer trials and two other trials). We then evaluated the relevance of the FIHT results for the 17 mAbs with the same dose calculation method in FIHT and RTs. The RP2D was tested in RTs of five mAbs (but only in two with the same schedule), and the MAD in RTs of four mAbs (Figure 3). The median RT dose/FIHT MAD ratio was 0.78 (range: 0.1 to 2.5). When considering the nine mAbs for which an RP2D was not available, at least one RT dose was lower than $75 \%$ of the MAD for six of them (specifically, lower than $50 \%$ for four mAbs and lower than $25 \%$ for one). We determined whether the top-three grade $3 / 4$ toxicities in the RTs of each $\mathrm{mAb}$ were reported in the corresponding FIHT, and their grade in the FIHT. For only seven 
Table 3. Rationale for tested dose selection in NFIHT without dose escalation

\begin{tabular}{|c|c|c|c|c|c|c|c|}
\hline \multicolumn{2}{|c|}{ References } & \multirow[t]{2}{*}{ mAb name } & \multicolumn{2}{|c|}{ FIHT } & \multicolumn{3}{|c|}{ NFIHT } \\
\hline FIHT & NFIHT & & MAD & RP2Ds & Dose & $\begin{array}{l}\text { Rationale } \\
\text { for dose } \\
\text { selection }\end{array}$ & $\begin{array}{l}\text { Rationale for dose } \\
\text { selection, details }\end{array}$ \\
\hline $\begin{array}{l}\text { Oberneder } \\
\text { et al, } 2006\end{array}$ & Schmidt et al, 2010 & Adecatumumab & $262 \mathrm{mg} \mathrm{m}^{-2} \mathrm{q} 2 \mathrm{w}$ & $\begin{array}{l}164 \mathrm{mg} \mathrm{m}^{-2} \mathrm{q} 2 \mathrm{w} \\
262 \mathrm{mg} \mathrm{m}^{-2} \mathrm{q} 2 \mathrm{w}\end{array}$ & $2,6 \mathrm{mg} \mathrm{kg}^{-1} \mathrm{q} 2 \mathrm{w}$ & See details & $\begin{array}{l}\text { The dosage regimen and } \\
\text { treatment duration selected } \\
\text { for this study were based on } \\
\text { PK modelling of the phase I } \\
\text { clinical study results in } \\
\text { patients with prostate cancer. }\end{array}$ \\
\hline $\begin{array}{l}\text { Oberneder } \\
\text { et al, } 2006\end{array}$ & Marschner et al, 2010 & Adecatumumab & $262 \mathrm{mg} \mathrm{m}^{-2} \mathrm{q} 2 \mathrm{w}$ & $\begin{array}{l}164 \mathrm{mg} \mathrm{m}^{-2} \mathrm{q} 2 \mathrm{w} \\
262 \mathrm{mg} \mathrm{m}^{-2} \mathrm{q} 2 \mathrm{w}\end{array}$ & $\begin{array}{c}2,6 \mathrm{mg} \mathrm{kg}^{-1} \mathrm{qw} \\
\times 3 \text { then } \mathrm{q} 2 \mathrm{w} \times \\
7\end{array}$ & See details & $\begin{array}{l}\text { A phase I trial in patients with } \\
\text { hormone-refractory prostate } \\
\text { cancer showed that } \\
\text { adecatumumab is well } \\
\text { tolerated with low } \\
\text { immunogenicity at doses up } \\
\text { to } 262 \mathrm{mg} \mathrm{m}^{-2} \\
\text { (approximately } 6.6 \mathrm{mg} \mathrm{kg}^{-1} \text { ) } \\
\text { every other week. }\end{array}$ \\
\hline $\begin{array}{l}\text { Furie et al, } \\
2008\end{array}$ & Bishton et al, 2013 & Belimumab & $20 \mathrm{mg} \mathrm{kg}^{-1} \mathrm{q} 3 \mathrm{w}$ & & $\begin{array}{l}10 \mathrm{mg} \mathrm{kg}^{-1} \mathrm{~d} 1 \\
15 \mathrm{q} 28 \text { then } \mathrm{q} 28\end{array}$ & See details & $\begin{array}{l}\text { These belimumab levels are } \\
\text { sufficient to neutralise the } \\
\text { cytokine BLYS and are similar } \\
\text { to those achieved in studies } \\
\text { conducted in systemic lupus } \\
\text { erythematous, in which an } \\
\text { average peak concentration } \\
\text { of } 192.4 \mathrm{mg} \mathrm{ml}^{-1} \text { was }^{-1} \\
\text { achieved at a } 10 \mathrm{mg} \mathrm{kg}^{-1} \\
\text { dose level. }\end{array}$ \\
\hline $\begin{array}{l}\text { Furie et al, } \\
2008\end{array}$ & $\begin{array}{l}\text { Wallace et al, } 2009 \\
\text { De Vita et al, } 2015\end{array}$ & Belimumab & $20 \mathrm{mg} \mathrm{kg}^{-1} \mathrm{q}^{3} \mathrm{w}$ & & $\begin{array}{l}10 \mathrm{mg} \mathrm{kg}^{-1} \mathrm{~d} 1 \\
15 \mathrm{q} 28 \text { then } \mathrm{q} 28\end{array}$ & NA & \\
\hline $\begin{array}{l}\text { Gordon } \\
\text { et al, } 2001\end{array}$ & $\begin{array}{l}\text { Ogita et al, 2012, } \\
\text { Schuster et al, } 2012\end{array}$ & Bevacizumab & $\begin{array}{l}10 \mathrm{mg} \mathrm{kg}^{-1} \mathrm{~d} 1 \\
\mathrm{~d} 28, \mathrm{~d} 35, \mathrm{~d} 42\end{array}$ & & $10 \mathrm{mg} \mathrm{kg}^{-1} \mathrm{q} 2 \mathrm{w}$ & See details & $\begin{array}{l}\text { The chosen dose was higher } \\
\text { than the doses used in } \\
\text { bevacizumab therapies for } \\
\text { normalisation of tumour } \\
\text { vasculature }\left(5 \mathrm{mg} \mathrm{kg}^{-1} \mathrm{q} 14 \mathrm{~d}\right) \\
\text { and in line with the dosing of } \\
\text { bevacizumab monotherapy } \\
\text { used in advanced renal } \\
\text { cancer where a survival } \\
\text { benefit was indicated } \\
\left.\text { (10 } \mathrm{mg} \mathrm{kg}^{-1} \mathrm{q} 14 \mathrm{~d}\right) \text {. }\end{array}$ \\
\hline $\begin{array}{l}\text { Baselga } \\
\text { et al, } 2000\end{array}$ & $\begin{array}{l}\text { Cunningham et al, } \\
\text { 2004, Pessino et al, } \\
\text { 2007, Neal et al, } \\
\text { 2010, Tabernero et al, } \\
\text { 2010, Maubec et al, } \\
\text { 2011, Wierzbicki et al, } \\
\text { 2011, Segelov et al, } \\
\text { 2016 }\end{array}$ & Cetuximab & $100 \mathrm{mg} \mathrm{m}^{-2} \mathrm{qw}$ & & $250 \mathrm{mg} \mathrm{m}^{-2} \mathrm{qw}$ & NA & \\
\hline $\begin{array}{l}\text { Atzori et al, } \\
2011\end{array}$ & $\begin{array}{l}\text { Reidy-Lagunes et al, } \\
2012\end{array}$ & Dalotuzumab & $20 \mathrm{mg} \mathrm{kg}^{-1} \mathrm{qw}$ & $\begin{array}{c}10 \mathrm{mg} \mathrm{kg}^{-1} \mathrm{qw} \\
20 \mathrm{mg} \mathrm{kg}^{-1} \mathrm{q} 2 \mathrm{w} \\
30 \mathrm{mg} \mathrm{kg}^{-1} \mathrm{q} 3 \mathrm{w}\end{array}$ & $10 \mathrm{mg} \mathrm{kg}^{-1} \mathrm{qw}$ & $\mathrm{RP} 2 \mathrm{D}$ in $\mathrm{FlHT}$ & \\
\hline $\begin{array}{l}\text { Trachtman } \\
\text { et al, } 2011\end{array}$ & Stevenson et al, 2013 & Fresolimumab & $\begin{array}{c}4 \mathrm{mg} \mathrm{kg}^{-1} \text { single } \\
\text { dose }\end{array}$ & & $3 \mathrm{mg} \mathrm{kg}^{-1} \mathrm{q} 3 \mathrm{w}$ & See details & $\begin{array}{l}\text { This dose was chosen based } \\
\text { on non-human primate } \\
\text { studies and data from the } \\
\text { previous phase I trial in } \\
\text { cancer, where an MTD up to } \\
15 \mathrm{mg} \mathrm{kg}^{-1} \text { was established, } \\
\text { but clinical responses were } \\
\text { observed in patients at doses } \\
\text { of } 1 \mathrm{mg} \mathrm{kg}^{-1} \text { or lower. }\end{array}$ \\
\hline
\end{tabular}




\section{Table 3. (Continued)}

\begin{tabular}{|c|c|c|c|c|c|c|c|}
\hline FIHT & NFIHT & mAb name & MAD & RP2Ds & Dose & $\begin{array}{l}\text { Rationale } \\
\text { for dose } \\
\text { selection }\end{array}$ & $\begin{array}{l}\text { Rationale for dose } \\
\text { selection, details }\end{array}$ \\
\hline $\begin{array}{l}\text { Tolcher et al, } \\
2009\end{array}$ & Tap et al, 2012 & Ganitumab & $20 \mathrm{mg} \mathrm{kg}^{-1} \mathrm{q}^{2} \mathrm{w}$ & & $12 \mathrm{mg} \mathrm{kg}^{-1} \mathrm{q} 2 \mathrm{w}$ & See details & $\begin{array}{l}\text { In the FIHT, this regimen was } \\
\text { tolerated, with a mean serum } \\
\text { trough concentration } \\
\left(42 \mu \mathrm{gll}^{-1}\right) \text { that exceeded } \\
\text { the } 90 \% \text { inhibitory } \\
\text { concentration }\left(28 \mu \mathrm{g} \mathrm{ml}^{-1}\right) \text { in } \\
\text { a human MiaPaCa-2 cell } \\
\text { xenograft model and } \\
\text { provided } 90 \% \text { IGF1R } \\
\text { receptor occupancy in a } \\
\text { surrogate tissue assay. }\end{array}$ \\
\hline $\begin{array}{l}\text { Tolcher et al, } \\
2009\end{array}$ & Strosberg et al, 2013 & Ganitumab & $20 \mathrm{mg} \mathrm{kg}^{-1} \mathrm{q} 2 \mathrm{w}$ & & $18 \mathrm{mg} \mathrm{kg}^{-1} \mathrm{q}^{3} \mathrm{w}$ & NA & \\
\hline $\begin{array}{l}\text { Genovese } \\
\text { et al, } 2010\end{array}$ & Leonardi et al, 2012 & Ixekizumab & $2 \mathrm{mg} \mathrm{kg}^{-1} \mathrm{q} 2 \mathrm{w}$ & & $\begin{array}{c}10,25,75 \\
150 \mathrm{mg} \mathrm{q} 2 \mathrm{w} 2 \times \\
\text { then } \mathrm{q} 4 \mathrm{w} \times 3\end{array}$ & NA & \\
\hline $\begin{array}{l}\text { Genovese } \\
\text { et al, } 2010\end{array}$ & Gordon et al, 2014 & Ixekizumab & $2 \mathrm{mg} \mathrm{kg}^{-1} \mathrm{q} 2 \mathrm{w}$ & & $120 \mathrm{mg} \mathrm{q} 1 \mathrm{~m}$ & NA & \\
\hline $\begin{array}{l}\text { Genovese } \\
\text { et al, } 2010\end{array}$ & Genovese et al, 2014 & Ixekizumab & $2 \mathrm{mg} \mathrm{kg}^{-1} \mathrm{q} 2 \mathrm{w}$ & & $\begin{array}{c}80 \mathrm{mg} \mathrm{q} 2 \mathrm{w}(12 w) \\
\text { then } q 4 w\end{array}$ & NA & \\
\hline $\begin{array}{l}\text { Tolcher et al, } \\
2009\end{array}$ & $\begin{array}{l}\text { Greco et al, 2008, } \\
\text { Trarbach et al, } 2010\end{array}$ & Mapatumumab & $10 \mathrm{mg} \mathrm{kg}^{-1} \mathrm{q}^{14}$ & & $10 \mathrm{mg} \mathrm{kg}^{-1} \mathrm{q}^{3} \mathrm{w}$ & See details & $\begin{array}{l}\text { The MTD was not identified } \\
\text { at doses up to } 20 \mathrm{mg} \mathrm{kg}^{-1} \\
\text { administered every } 28 \text { days. } \\
\text { Stable disease was observed } \\
\text { in a number of heavily } \\
\text { pretreated patients at several } \\
\text { dose levels. Therefore, } \\
10 \mathrm{mg} \mathrm{kg}^{-1} \text { was considered a } \\
\text { safe and potentially effective } \\
\text { dose for the treatment of } \\
\text { non-small cell lung cancer. }\end{array}$ \\
\hline $\begin{array}{l}\text { Yamamoto } \\
\text { et al, } 2010\end{array}$ & Ishida et al, 2012 & & mogamulizumab & $1 \mathrm{mg} \mathrm{kg}^{-1} \mathrm{qw}$ & $1 \mathrm{mg} \mathrm{kg}^{-1} \mathrm{qw}$ & $1 \mathrm{mg} \mathrm{kg}^{-1} \mathrm{qw}$ & RP2D in FIHT \\
\hline $\begin{array}{l}\text { Brahmer } \\
\text { et al, } 2010\end{array}$ & $\begin{array}{l}\text { Gardiner et al, 2013, } \\
\text { Borghaei et al, 2015, } \\
\text { Brahmer et al, 2015, } \\
\text { Hamanishi et al, 2015, } \\
\text { Motzer et al, 2015a, } \\
\text { 2015b, Rizvi et al, } \\
2015, \text { Robert et al, } \\
2015, \text { Weber et al, } \\
2015\end{array}$ & Nivolumab & $10 \mathrm{mg} \mathrm{kg}^{-1} \mathrm{q} 2 \mathrm{w}$ & & $3 \mathrm{mg} \mathrm{kg}^{-1} \mathrm{q} 2 \mathrm{w}$ & NA & \\
\hline $\begin{array}{l}\text { Salles et al, } \\
2012\end{array}$ & $\begin{array}{l}\text { Morschhauser et al, } \\
\text { 2013, Salles et al, } \\
2013\end{array}$ & Obinutuzumab & $\begin{array}{c}1200 / 2000 \mathrm{mg} \\
\mathrm{d} 1,8,21, \text { then } \\
q 3 \mathrm{w}\end{array}$ & $\begin{array}{c}400 / 400,1600 / \\
800 \mathrm{mg} \text { d1 }, 8,21 \\
\text { then } \mathrm{q}^{3} \mathrm{w}\end{array}$ & $\begin{array}{c}400 / 400,1600 / \\
800 \mathrm{mg} d 1,8,21 \\
\text { then } \mathrm{q}^{3} \mathrm{w}\end{array}$ & $\mathrm{RP} 2 \mathrm{D}$ in $\mathrm{FIHT}$ & $\begin{array}{l}\text { We based the dose and } \\
\text { schedule of nivolumab on } \\
\text { safety and activity data from a } \\
\text { phase } 1 \text { study that showed a } \\
\text { similar proportion of } \\
\text { objective responses in } \\
\text { patients treated with } \\
3 \mathrm{mg} \mathrm{kg}^{-1} \text { or with } \\
10 \mathrm{mg} \mathrm{kg}^{-1} ; \text { both doses } \\
\text { achieved better responses } \\
\text { than the } 1 \mathrm{mg} \mathrm{kg}{ }^{-1} \text { dose. } \\
\text { The safety profile was similar } \\
\text { with each dose and for } \\
\text { different tumour types in the } \\
\text { phase } 1 \text { trial. }\end{array}$ \\
\hline
\end{tabular}




\section{Table 3. (Continued)}

\begin{tabular}{|c|c|c|c|c|c|c|c|}
\hline \multicolumn{2}{|c|}{ References } & \multirow[t]{2}{*}{ mAb name } & \multicolumn{2}{|c|}{ FIHT } & \multicolumn{3}{|c|}{ NFIHT } \\
\hline FIHT & NFIHT & & MAD & RP2Ds & Dose & $\begin{array}{l}\text { Rationale } \\
\text { for dose } \\
\text { selection }\end{array}$ & $\begin{array}{l}\text { Rationale for dose } \\
\text { selection, details }\end{array}$ \\
\hline $\begin{array}{l}\text { Salles et al, } \\
2012\end{array}$ & $\begin{array}{l}\text { Cartron et al, 2014, } \\
\text { Byrd et al, } 2016\end{array}$ & Obinutuzumab & $\begin{array}{c}1200 / 2000 \mathrm{mg} \\
\mathrm{d} 1,8,21, \text { then } \\
q^{3} w\end{array}$ & $\begin{array}{c}400 / 400,1600 / \\
800 \mathrm{mg} \mathrm{d} 1,8,21 \\
\text { then } \mathrm{q} 3 \mathrm{w}\end{array}$ & $\begin{array}{c}1000 \mathrm{mg} \mathrm{d} 1,8,15 \\
\text { then } \mathrm{q}^{3} \mathrm{w}\end{array}$ & NA & \\
\hline $\begin{array}{l}\text { Hagenbeek } \\
\text { et al, } 2008\end{array}$ & Wierda et al, 2010 & Ofatumumab & $1000 \mathrm{mg} \mathrm{qw}$ & $\begin{array}{l}500 \mathrm{mg} \mathrm{qw}, \\
1000 \mathrm{mg} \text { qw }\end{array}$ & $\begin{array}{c}300 / 2000 \mathrm{mg} \mathrm{qw} \\
\times 8 \text { then } \mathrm{q} 4 \mathrm{w} \times \\
4\end{array}$ & NA & \\
\hline $\begin{array}{l}\text { Hagenbeek } \\
\text { et al, } 2008\end{array}$ & Coiffier et al, 2013 & Ofatumumab & $1000 \mathrm{mg} \mathrm{qw}$ & $\begin{array}{l}500 \mathrm{mg} \mathrm{qw} \\
1000 \mathrm{mg} \text { qw }\end{array}$ & $300 / 1000 \mathrm{mg} \mathrm{qw}$ & $\mathrm{RP} 2 \mathrm{D}$ in $\mathrm{FIHT}$ & \\
\hline $\begin{array}{l}\text { Hagenbeek } \\
\text { et al, } 2008\end{array}$ & Czuczman et al, 2012 & Ofatumumab & $1000 \mathrm{mg} \mathrm{qw}$ & $\begin{array}{l}500 \mathrm{mg} \mathrm{qw}, \\
1000 \mathrm{mg} \mathrm{qw}\end{array}$ & $500,1000 \mathrm{mg} \mathrm{qw}$ & $\mathrm{RP} 2 \mathrm{D}$ in $\mathrm{FIHT}$ & \\
\hline $\begin{array}{l}\text { Hagenbeek } \\
\text { et al, } 2008\end{array}$ & Furtado et al, 2014 & Ofatumumab & $1000 \mathrm{mg} \mathrm{qw}$ & $\begin{array}{l}500 \mathrm{mg} \mathrm{qw} \\
1000 \mathrm{mg} \mathrm{qw}\end{array}$ & $1000 \mathrm{mg} \mathrm{qw}$ & $\mathrm{RP} 2 \mathrm{D}$ in FIHT & \\
\hline $\begin{array}{l}\text { Emu et al, } \\
2012\end{array}$ & Kennedy et al, 2014 & Pateclizumab & $3 \mathrm{mg} \mathrm{q} 2 \mathrm{w}$ & & $360 \mathrm{mg} \mathrm{q} 2 \mathrm{w}$ & See details & $\begin{array}{l}\text { Based on safety and efficacy } \\
\text { data from a phase I/II study in } \\
\text { patients with chronic } \\
\text { lymphocytic leukaemia. }\end{array}$ \\
\hline Agus, 2005 & $\begin{array}{l}\text { Gordon et al, 2006, } \\
\text { De Bono et al, 2007, } \\
\text { Gianni et al, } 2010\end{array}$ & Pertuzumab & $15 \mathrm{mg} \mathrm{kg}^{-1} \mathrm{q} 3 \mathrm{w}$ & $420 \mathrm{mg} q^{3} \mathrm{w}$ & $\begin{array}{c}840 / 420 \\
1050 \mathrm{mg} \mathrm{q} 3 \mathrm{w}\end{array}$ & $\begin{array}{c}\text { MAD and } \\
\text { RP2D in FIHT }\end{array}$ & $\begin{array}{l}\text { This study regimen was } \\
\text { selected based on the } \\
\text { following considerations: (1) } \\
\text { total exposure was, on } \\
\text { average, } 60 \% \mathrm{higher}^{-} \text {than } \\
\text { with the } 3 \mathrm{mg} \mathrm{kg}^{-1} \text { biweekly } \\
\text { subcutaneaously doses } \\
\text { evaluated in the } \\
\text { pateclizumab phase I study; } \\
\text { (2) this regimen was expected } \\
\text { to result in a maximal }\end{array}$ \\
\hline
\end{tabular}




\section{Table 3. (Continued)}

\begin{tabular}{|c|c|c|c|c|c|c|c|}
\hline FIHT & NFIHT & mAb name & MAD & RP2Ds & Dose & $\begin{array}{l}\text { Rationale } \\
\text { for dose } \\
\text { selection }\end{array}$ & $\begin{array}{l}\text { Rationale for dose } \\
\text { selection, details }\end{array}$ \\
\hline & & & & & & & $\begin{array}{l}\text { pharmacological effect as } \\
\text { suggested by plateaued } \\
\text { reductions in serum CXCL13 } \\
\text { level in all dose groups at } \\
1 \mathrm{mg} \mathrm{kg}^{-1} \text { or higher doses; } \\
\text { and (3) this regimen has } 2.2- \\
\text { to } 4.5 \text {-fold exposure safety } \\
\text { coverage by the highest } \\
\text { exposure level assessed in } \\
\text { the phase I study. }\end{array}$ \\
\hline Agus, 2005 & Agus et al, 2007 & Pertuzumab & $15 \mathrm{mg} \mathrm{kg}^{-1} \mathrm{q} 3 \mathrm{w}$ & $420 \mathrm{mg} \mathrm{q} 3 \mathrm{w}$ & $840 / 420 \mathrm{mg} \mathrm{q3w}$ & RP2D in FIHT & 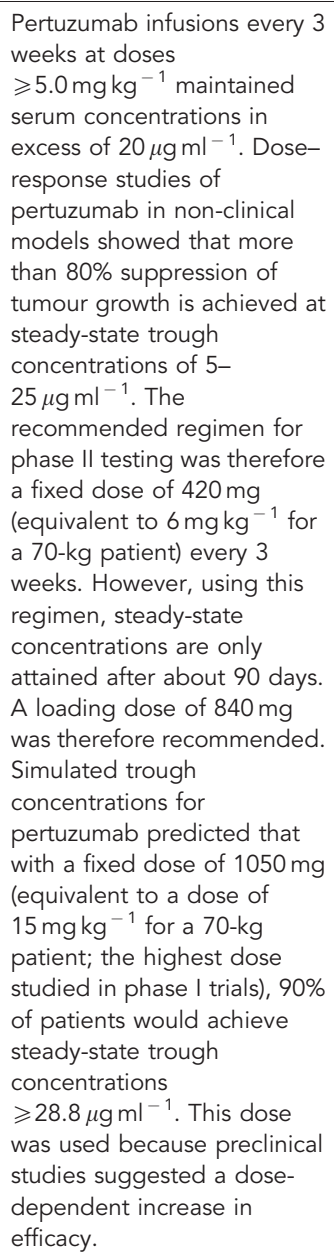 \\
\hline Agus, 2005 & Herbst et al, 2007 & Pertuzumab & $15 \mathrm{mg} \mathrm{kg}^{-1} \mathrm{q} 3 \mathrm{w}$ & $420 \mathrm{mg} \mathrm{q} 3 \mathrm{w}$ & $840 / 420 \mathrm{mg} \mathrm{q3w}$ & RP2D in FIHT & \\
\hline $\begin{array}{l}\text { Berger et al, } \\
2008\end{array}$ & Armand et al, 2013 & Pidilizumab & $\begin{array}{c}6 \mathrm{mg} \mathrm{kg}^{-1} \text { single } \\
\text { dose }\end{array}$ & $\begin{array}{c}1 \mathrm{mg} \mathrm{kg}^{-1} \text { single } \\
\text { dose }\end{array}$ & $1.5 \mathrm{mg} \mathrm{kg}^{-1} \mathrm{q} 42$ & NA & \\
\hline $\begin{array}{l}\text { Díaz et al, } \\
2003\end{array}$ & Alfonso et al, 2007 & Racotumomab & $2 m g ~ q 2 w$ & & $\begin{array}{c}1 \mathrm{mg} \mathrm{q} 2 \mathrm{w} \times 5 \\
\text { then } \mathrm{q} 4 \mathrm{w}\end{array}$ & NA & \\
\hline $\begin{array}{l}\text { Díaz et al, } \\
2003\end{array}$ & Alfonso et al, 2014 & Racotumumab & $2 m g ~ q 2 w$ & & $\begin{array}{l}1 \mathrm{mg} \mathrm{q} 2 \mathrm{w} \times 5 \\
\text { then } \mathrm{q} 4 \mathrm{w} \times 10\end{array}$ & NA & \\
\hline $\begin{array}{l}\text { Díaz et al, } \\
2003\end{array}$ & Neninger et al, 2007 & Racotumumab & $2 m g ~ q 2 w$ & & $\begin{array}{l}2 \mathrm{mg} \mathrm{q} 2 \mathrm{w} \times 5 \\
\text { then } \mathrm{q} 4 \mathrm{w} 6 \times\end{array}$ & NA & \\
\hline $\begin{array}{l}\text { Spratlin } \\
\text { et al, } 2010\end{array}$ & $\begin{array}{l}\text { Zhu et al, 2013, Fuchs } \\
\text { et al, 2014, Garcia } \\
\text { et al, 2014, Penson } \\
\text { et al, 2014 }\end{array}$ & Ramucirumab & $\begin{array}{l}16 \mathrm{mg} \mathrm{kg}^{-1} \mathrm{~d} 1 \\
15 \text { then } \mathrm{q} 2 \mathrm{w}\end{array}$ & $\begin{array}{c}8 \mathrm{mg} \mathrm{kg}^{-1} \mathrm{~d} 1,15 \\
\text { then } \mathrm{q} 2 \mathrm{w}\end{array}$ & $8 \mathrm{mg} \mathrm{kg}^{-1} \mathrm{q} 2 \mathrm{w}$ & $\mathrm{RP} 2 \mathrm{D}$ in FIHT & \\
\hline $\begin{array}{l}\text { Spratlin } \\
\text { et al, } 2010\end{array}$ & Carvajal et al, 2014 & Ramucirumab & $\begin{array}{l}16 \mathrm{mg} \mathrm{kg}^{-1} \mathrm{~d} 1 \\
15 \text { then } \mathrm{q} 2 \mathrm{w}\end{array}$ & $\begin{array}{c}8 \mathrm{mg} \mathrm{kg}^{-1} \mathrm{~d} 1,15 \\
\text { then } \mathrm{q} 2 \mathrm{w}\end{array}$ & $10 \mathrm{mg} \mathrm{kg}^{-1} \mathrm{q}^{3 \mathrm{w}}$ & NA & $\begin{array}{l}\text { A phase II dose of } 8 \mathrm{mg} \mathrm{kg}^{-1} \\
\text { every } 2 \text { weeks was selected } \\
\text { because it was associated } \\
\text { with the minimum drug }\end{array}$ \\
\hline
\end{tabular}




\section{Table 3. (Continued)}

\begin{tabular}{|c|c|c|c|c|c|c|c|}
\hline FIHT & NFIHT & mAb name & MAD & RP2Ds & Dose & $\begin{array}{l}\text { Rationale } \\
\text { for dose } \\
\text { selection }\end{array}$ & $\begin{array}{l}\text { Rationale for dose } \\
\text { selection, details }\end{array}$ \\
\hline & & & & & & & $\begin{array}{l}\text { concentrations that } \\
\text { exceeded the levels } \\
\text { associated with tumour } \\
\text { growth inhibition in } \\
\text { preclinical models and with } \\
\text { PK profiles suggesting } \\
\text { receptor saturation, and } \\
\text { because preliminary efficacy } \\
\text { was observed across a range } \\
\text { of phase I doses and } \\
\text { schedules. }\end{array}$ \\
\hline $\begin{array}{l}\text { Paz-Ares } \\
\text { et al, } 2011\end{array}$ & Delord et al, 2014 & RGT160 & $\begin{array}{l}1400 \mathrm{mg} d 1, \mathrm{~d} 8 \\
\text { then } \mathrm{q} 2 \mathrm{w}\end{array}$ & $\begin{array}{l}1400 \mathrm{mg} \mathrm{d} 1, \mathrm{~d} 8 \\
\text { then } \mathrm{q} 2 \mathrm{w}\end{array}$ & $\begin{array}{l}1400 \mathrm{mg} d 1, \mathrm{~d} 8 \\
\text { then } \mathrm{q} 2 \mathrm{w}\end{array}$ & RP2D & \\
\hline $\begin{array}{l}\text { Bartlett et al, } \\
2008\end{array}$ & $\begin{array}{l}\text { Forero-Torres et al, } \\
2010\end{array}$ & SGN-30 & $12 \mathrm{mg} \mathrm{kg}^{-1} \mathrm{qw}$ & $6 \mathrm{mg} \mathrm{kg}^{-1} \mathrm{qw}$ & $\begin{array}{c}6,12 \mathrm{mg} \mathrm{kg}^{-1} \mathrm{qw} \\
\times 6 \text { then } 2 \text { weeks } \\
\text { off }\end{array}$ & $\begin{array}{c}\text { MAD in FIHT, } \\
\text { see details }\end{array}$ & \\
\hline $\begin{array}{l}\text { Bartlett et al, } \\
2008\end{array}$ & Duvic et al, 2009 & SGN-30 & $12 \mathrm{mg} \mathrm{kg}^{-1} \mathrm{qw}$ & $6 \mathrm{mg} \mathrm{kg}^{-1} \mathrm{qw}$ & $\begin{array}{l}4,12 \mathrm{mg} \mathrm{kg}^{-1} \\
\mathrm{q} 2 \mathrm{w} / \mathrm{q} 3 \mathrm{w}\end{array}$ & See details & $\begin{array}{l}\text { Based on the assessment of } \\
\text { rilotumumab serum } \\
\text { concentration in the FIHT and } \\
\text { values of } 90 \% \text { inhibitory } \\
\text { concentrations predicted in } \\
\mathrm{U}-87 \mathrm{MG} \text { glioblastoma cell } \\
\text { proliferation assays, } \\
10 \mathrm{mg} \mathrm{kg}^{-1} \text { was selected as } \\
\text { the starting dose. }\end{array}$ \\
\hline $\begin{array}{l}\text { Scott et al, } \\
2003\end{array}$ & Hofheinz et al, 2003 & Sibrotuzumab & $50 \mathrm{mg} \mathrm{m}^{-2} \mathrm{qw}$ & & $100 \mathrm{mg} \mathrm{qw}$ & NA & $\begin{array}{l}\text { The first } 40 \text { patients enrolled } \\
\text { in the study (15 in the } \\
\text { Hodgkin lymphoma group } \\
\text { and } 25 \text { in the anaplastic large } \\
\text { cell lymphoma group) } \\
\text { received SGN-30 at } \\
6 \mathrm{mg} \mathrm{kg}^{-1} \text { weekly. To } \\
\text { increase the objective } \\
\text { response rates and after an } \\
\text { interim analysis of the safety } \\
\text { data and review of the } \\
\text { response data from the } \\
\text { previous phase I study, SGN- } \\
30 \text { dose was increased to } \\
12 \mathrm{mg} \mathrm{kg}^{-1} \text { weekly for the } \\
\text { remaining patients. }\end{array}$ \\
\hline $\begin{array}{l}\text { Rosen et al, } \\
2012\end{array}$ & Duffy et al, 2015 & TRC105 & $15 \mathrm{mg} \mathrm{kg}^{-1} \mathrm{qw}$ & $\begin{array}{c}10 \mathrm{mg} \mathrm{kg}^{-1} \mathrm{qw} \text { or } \\
15 \mathrm{mg} \mathrm{kg}^{-1} \mathrm{q} 2 \mathrm{w}\end{array}$ & $15 \mathrm{mg} \mathrm{kg}^{-1} \mathrm{q} 2 \mathrm{w}$ & RP2D & $\begin{array}{l}\text { The first six patients enrolled } \\
\text { received six doses (one } \\
\text { course) of SGN-30 at } \\
4 \mathrm{mg} \mathrm{kg}^{-1} \text { administered as } \\
\text { i.v. infusion every } 2-3 \text { weeks. } \\
\text { If there was no response, the } \\
\text { dose could be increased to } \\
12 \mathrm{mg} \mathrm{kg}^{-1} \text {. A protocol } \\
\text { amendment increased the } \\
\text { starting dose to } 12 \mathrm{mg} \mathrm{kg}^{-1} \text {, } \\
\text { which was given to } 17 \\
\text { patients. }\end{array}$ \\
\hline $\begin{array}{l}\text { Herbst et al, } \\
2009\end{array}$ & $\mathrm{D}^{\prime}$ Angelo et al, 2015 & Trebananib & $30 \mathrm{mg} \mathrm{kg}^{-1} \mathrm{qw}$ & $30 \mathrm{mg} \mathrm{kg}^{-1} \mathrm{qw}$ & $30 \mathrm{mg} \mathrm{kg}^{-1} \mathrm{qw}$ & $\mathrm{RP} 2 \mathrm{D}$ in FIHT & \\
\hline $\begin{array}{l}\text { Herbst et al, } \\
2009\end{array}$ & Moore et al, 2015 & Trebananib & $30 \mathrm{mg} \mathrm{kg}^{-1} \mathrm{qw}$ & $30 \mathrm{mg} \mathrm{kg}^{-1} \mathrm{qw}$ & $15 \mathrm{mg} \mathrm{kg}^{-1} \mathrm{qw}$ & NA & \\
\hline Ribas, 2005 & $\begin{array}{l}\text { Chung et al, 2010, } \\
\text { Kirkwood et al, 2010, } \\
\text { Ralph et al, 2010, } \\
\text { Sangro et al, } 2013\end{array}$ & Tremelimumab & $\begin{array}{l}15 \mathrm{mg} \mathrm{kg}^{-1} \\
\text { single dose }\end{array}$ & & $15 \mathrm{mg} \mathrm{kg}^{-1} \mathrm{q} 90$ & NA & \\
\hline
\end{tabular}




\section{Table 3. (Continued)}

\begin{tabular}{|c|c|c|c|c|c|c|c|}
\hline \multicolumn{2}{|c|}{ References } & \multirow[t]{2}{*}{ mAb name } & \multicolumn{2}{|c|}{ FIHT } & \multicolumn{3}{|c|}{ NFIHT } \\
\hline FIHT & NFIHT & & MAD & RP2Ds & Dose & $\begin{array}{l}\text { Rationale } \\
\text { for dose } \\
\text { selection }\end{array}$ & $\begin{array}{l}\text { Rationale for dose } \\
\text { selection, details }\end{array}$ \\
\hline $\begin{array}{l}\text { Norman } \\
\text { et al, } 2000\end{array}$ & Sandborn et al, 2010 & Visilizumab & $\begin{array}{l}0.015 \mathrm{mg} \mathrm{kg}^{-1} \\
\text { (once) }\end{array}$ & & $5 \mu \mathrm{g} \mathrm{kg}^{-1} \mathrm{~d} 1, \mathrm{~d} 2$ & See details & $\begin{array}{l}\text { A phase I/II trial was } \\
\text { conducted to evaluate the } \\
\text { safety and efficacy of multi- } \\
\text { dose tremelimumab } \\
\text { regimens. In the phase II } \\
\text { portion of the study, patients } \\
(n=89) \text { received } 15 \mathrm{mg} \mathrm{kg}^{-1} \\
\text { administered every } 90 \text { days } \\
\text { or } 10 \mathrm{mg} \mathrm{kg}^{-1} \text { every month. } \\
\text { The } 15 \mathrm{mg} \mathrm{kg}^{-1} \text { every } 90 \\
\text { days regimen was selected } \\
\text { for further development } \\
\text { based on the incidence of } \\
\text { grade } 3 / 4 \text { adverse events } \\
(13 \% \text { with } 15 \text { mg kg } \\
90 \text { days vs and } 27 \% \text { with } \\
10 \mathrm{mg} \mathrm{kg}^{-1} \text { every month, } \\
\text { respectively) and serious } \\
\text { adverse events ( } 9 \% \text { and } \\
25 \%) .\end{array}$ \\
\hline $\begin{array}{l}\text { Ricart et al, } \\
2008\end{array}$ & $\begin{array}{l}\text { Bell-McGuinn et al, } \\
2011\end{array}$ & Volociximab & $\begin{array}{c}15 \mathrm{mg} \mathrm{kg}^{-1} \mathrm{~d} 1 \\
15,22,29,36 \\
\text { then qw }\end{array}$ & & $15 \mathrm{mg} \mathrm{kg}^{-1} \mathrm{qw}$ & MAD in FIHT & $\begin{array}{l}\text { In a phase I study, visilizumab } \\
\text { was well tolerated in patients } \\
\text { with steroid-resistant acute } \\
\text { graft vs host disease, and } \\
\text { improvement was } \\
\text { documented in } 10 \text { of } 11 \\
\text { patients who received a } \\
\text { single dose }\left(3 \mathrm{mg} \mathrm{m}^{-2}\right) \text { of } \\
\text { visilizumab. }\end{array}$ \\
\hline
\end{tabular}

Abbreviations: $F I H T=$ first-in-human trial; $m A b=$ monoclonal antibody; $M A D=$ maximum administered dose; $M T D=$ maximum tolerated dose; $N F I H T=$ non-first-in-human trial; $P K=$ pharmacokinetics; RP2D = recommended phase II dose; $q w=$ one a week; $q 2 w=$ every 2 weeks; $q 3 w=$ every 3 weeks; $q 4 w=$ every 4 weeks; $q m=e v e r y$ month.

mAbs (25\%) at least two of the top-three RT grade 3/4 toxicities were reported as grade 3/4 in FIHT. Conversely, for 16 (57\%) none of the top-three grade $3 / 4$ toxicities described in the RTs was reported as grade $3 / 4$ in FIHT. In addition, for seven $(25 \%)$ of mAbs none of the top-three grade $3 / 4$ toxicities was reported in FIHT.

\section{DISCUSSION}

In our previous analysis concerning the FIHTs of mAbs published between 2000 and 2013, we showed that, for most of the tested molecules, acute toxicity events were rarely observed and did not allow the identification of an MTD. This frequently led to doubtful or questionable recommendations about the RP2D that was determined on the basis of surrogate endpoints (Tosi et al, 2015). Here, we analysed the NFIHTs of the same mAbs to evaluate how these trials used the FIHT-derived results, particularly the FIHT RP2D and MAD. We also investigated whether the FIHT results were relevant in the case of FDA-approved mAbs, relative to the tested doses and toxicities observed in RTs.

In the examined dose escalation NFIHTs, the dose level scheme was conservative relative to the FIHT, severe toxicities were infrequent, the MTD was rarely determined and the RP2D was indicated in a minority of trials. In addition, the rationale for RP2D selection was infrequently available and not always stringent, when present. These results indicate that even when a dose escalation trial for an $\mathrm{mAb}$ is performed in post-FIHT settings, a significant uncertainty persists over the RP2D indication. Moreover, we found that the FIHT RP2D had a limited influence on dose selection in phase II-III NFIHTs. This is in striking contrast with what generally occurs in anticancer drug development, where the final FDA-approved dose is within $20 \%$ on either side of the FIHT RP2D in $73 \%$ of cases (Jardim et al, 2014). In addition, the FIHT MAD was frequently tested in trials of $\mathrm{mAb}$ with available RP2D, suggesting a lack of confidence in the RP2D selection criteria. On the other hand, the FIHT MAD constituted a widely accepted upper limit for dose selection in phase II-III NFIHTs. Frequently, we could not retrieve a convincing justification for dose selection in NFIHTs of mAbs. In a significant percentage of trials, the dose tested in NFIHTs without dose escalation did not correspond to the RP2D or MAD and no rationale for dose selection was available, which did not allow evaluating whether the assumptions underlying the choice were appropriate. When the FIHT RP2D or MAD was not used to inform decisions about the dose to be tested in NFIHTs, preclinical data on the drug effective concentration and clinical PK data were frequently the parameters of choice, notably the serum concentrations attained in clinical trials. However, due to their size, mAb penetration in tissues occurs mainly by convective transport and is characterised by slow diffusion rates in tumour tissue (Tabrizi et al, 2010; Dostalek et al, 2013; Tibbitts et al, 2016). This poor tumour uptake is mostly explained by the scarce tumour vascularisation and the increased interstitial fluid pressure, secondary to vessel abnormalities, fibrosis and interstitial matrix contraction (Heldin et al, 2004). Consequently, it appears hazardous to simply infer the mAb tumour tissue concentration from their serum level.

The lack of association between the most frequent severe toxicities in FIHT and RTs suggests that the FIHT results are not useful to predict the actual mAb toxicity and that, consequently, an approach based on a toxicity-guided dose selection during the early clinical development of mAbs could be misguiding. Moreover, the 
A

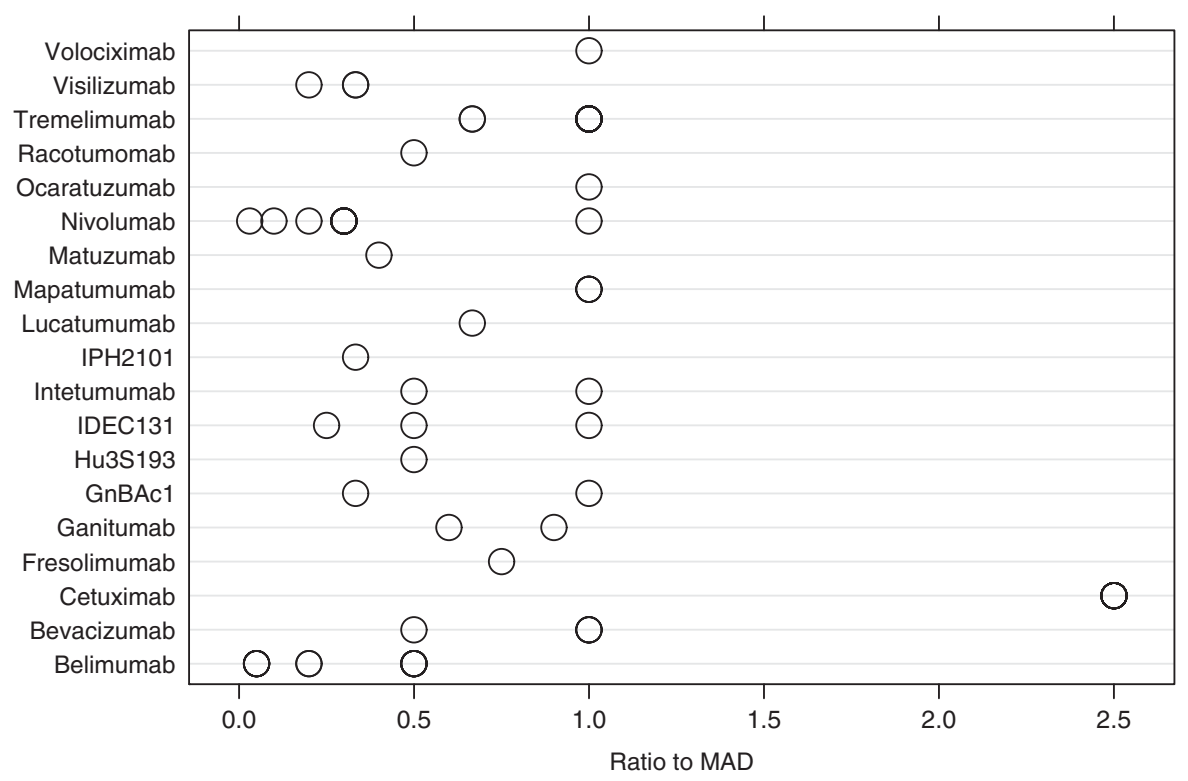

B

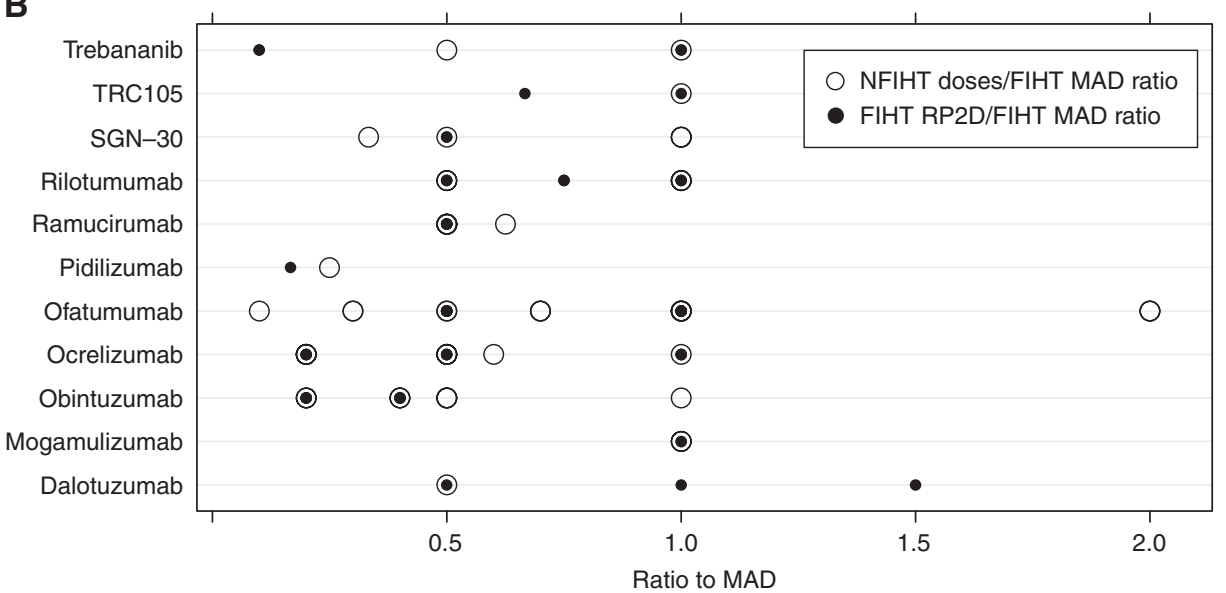

Figure 2. Ratio between the phase II/III NFIHT doses and the FIHT MAD. (A) Ratio between the dose tested in NFIHT and the FIHT MAD for each mAb without an FIHT RP2D. Circles represents the ratio between the tested dose of each mAb and the relevant FIHT MAD. Each circle refers to a dose tested in one or more NFIHTs. The names of tested mAb are indicated on the left. (B) Ratio between the dose tested in NFIHT and the FIHT MAD for each mAb with an FIHT RP2D. Hollow circles represent the ratio between the tested dose of each mAb and the relevant FIHT MAD. Each circle refers to a dose tested in one or more NFIHTs. Filled circles represent the ratio between the FIHT RP2D and the FIHT MAD. The names of tested $\mathrm{mAb}$ are indicated on the left. FIHT=first-in-human trial; $M A D=$ maximum administered dose; NFIHT=non-first-in-human trial;

$\mathrm{RP} 2 \mathrm{D}=$ recommended phase $\|$ dose.

absence of significant toxicity in FIHTs could complicate the choice of the doses to be tested in later trials. Selecting an unnecessarily high $\mathrm{mAb}$ dose can be unsafe because rare dosedependent toxicities could appear later during the drug development process. Inappropriately low doses also can affect efficacy and tolerability because, in the presence of an abundant target mass, the $\mathrm{mAb}$ PK could be altered due to target-mediated drug disposition (Cartron et al, 2016; Meulendijks et al, 2016), especially when the $\mathrm{mAb}$ target is also expressed in healthy tissues (Azzopardi et al, 2011).

Other approaches for optimal mAb dose selection could be suggested, such as correlating the mAb serum concentration with PD marker variations, or implementing PK/PD models. The choice and accessibility to the measured PD markers are crucial in this setting. Quantitative data on serum (soluble) mAb targets, receptor occupancy on circulating tumour cells, serum markers that indirectly reflect the mAb effect (Mayer et al, 2015), or clinical parameters directly linked to disease activity (Azzopardi et al,
2015) represent useful PD endpoints for clinical trials. However, for mAbs that alter intracellular signalling, PD marker assessment in tumour cells is an elusive endpoint due to the limited availability of repeated biopsies. Integrative evaluations, including gene expression and phosphokinome profiling in tumour samples and liquid biopsies, could represent suitable tools for dose-finding clinical trials when preclinical studies have established clear correlations between a molecular signature and drug efficacy.

In addition, we previously showed that in mAb FIHTs the safety data relevant for dose selection are collected during a short observation window, which frequently corresponds to the first cycle of treatment (Tosi et al, 2015). Indeed, mAb PK could be far from the steady state throughout this time, because of the long drug half-life and dosing schedules that are frequently at least weekly (Tosi et al, 2015). In addition, the effect of target-mediated drug disposition (Azzopardi et al, 2011), and the rare administration of loading doses (Tosi et al, 2015) could contribute to delay reaching the maximal serum concentrations. Consequently, 
A

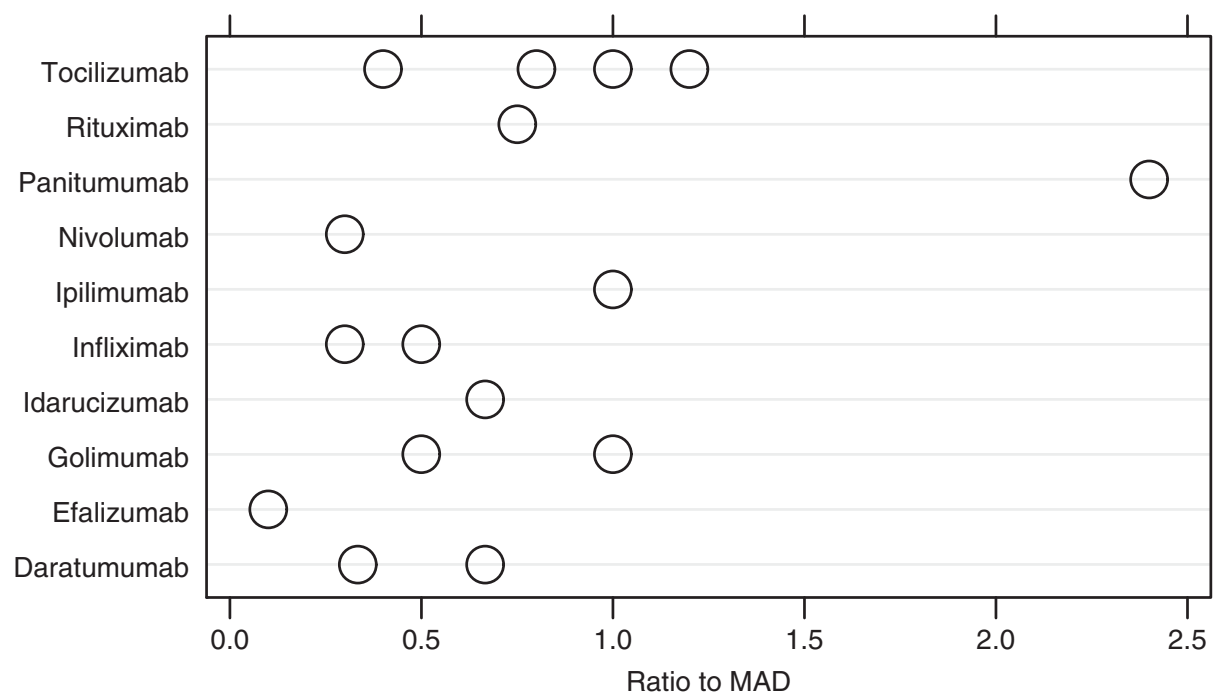

B

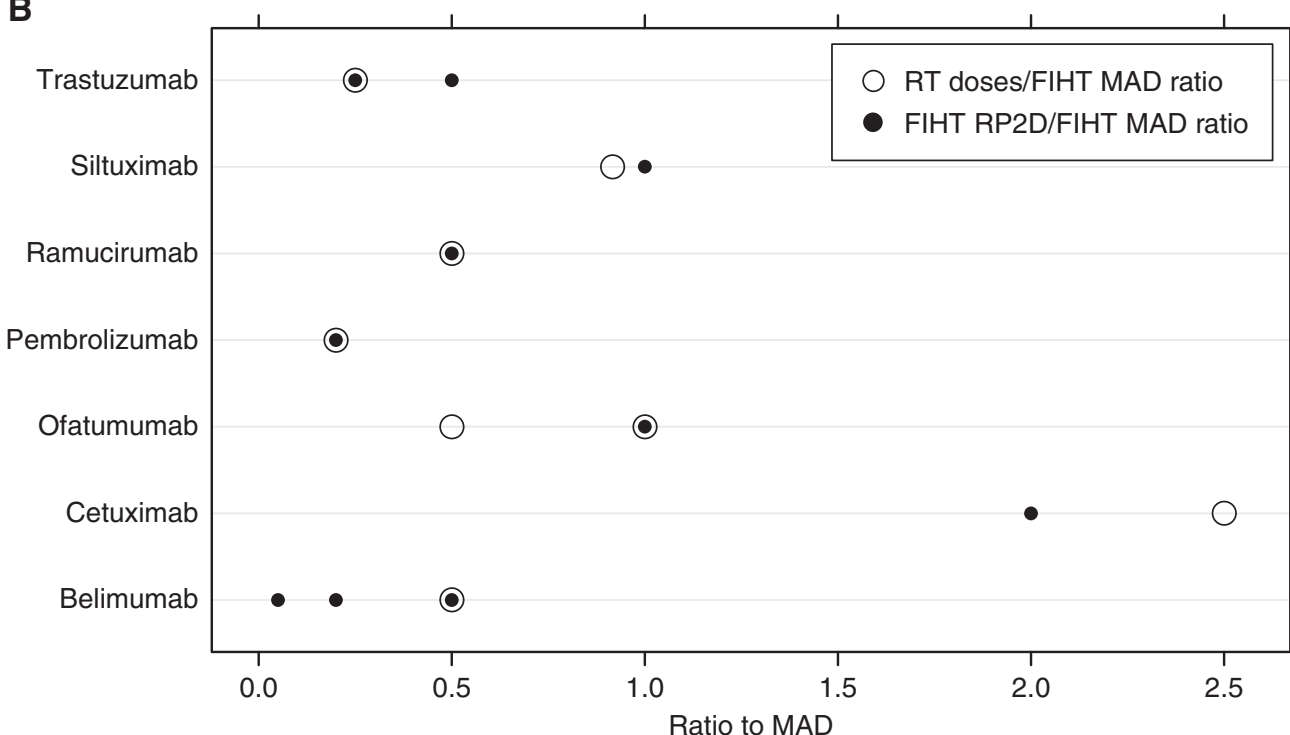

Figure 3. Ratio between RT doses and FIHT MAD. (A) Ratio between the dose tested in RT and the FIHT MAD for each mAb without an FIHT RP2D. Circles represent the ratio between the tested dose of each mAb and the relevant FIHT MAD. Each circle refers to a dose tested in one or more RTs. The names of tested mAb are indicated on the left. (B) Ratio between the dose tested in RT and the FIHT MAD for each mAb with an FIHT RP2D. Hollow circles represent the ratio between the tested dose of each mAb and the relevant FIHT MAD. Each circle refers to a dose tested in one or more RTs. Filled circles represent the ratio between the FIHT RP2D and the FIHT MAD. The names of tested mAb are indicated on the left. FIHT=first-in-human trial; $M A D=$ maximum administered dose; NFIHT=non-first-in-human trial; RP2D=recommended phase II dose; RT=registration trial.

safety data or PK or PD evaluations obtained in this setting have limited value, suggesting that trial designs including a longer time frame for endpoint assessment at selected doses could be more appropriate.

\section{CONCLUSIONS}

We show that the results of FIHTs, particularly standard FIHT endpoints such as MAD, MTD and RP2D, are frequently not taken into account for the design of later clinical studies on mAbs. Moreover, while safety is the main endpoint of mAb FIHTs, other pharmacological aspects are often considered for dose choice in later clinical trials, although the relevance of these surrogate endpoints relative to the $\mathrm{mAb}$ clinical activity is questionable. New clinical development strategies are urgently needed for this class of molecules characterised by scarce toxicity, specific PK and high therapeutic potential. Particularly, these data strongly support shorter and more PD-focused phase I studies, as well as randomised phase II studies to compare different $\mathrm{mAb}$ doses.

\section{ACKNOWLEDGEMENTS}

The authors thank Elisabetta Andermarcher, $\mathrm{MD}, \mathrm{PhD}$, for editorial assistance. Supported by the French Health Ministry Program 'Investissements d'avenir' (grant LabEx MAbImprove').

\section{CONFLICT OF INTEREST}

The authors declare no conflict of interest. 


\section{REFERENCES}

Agus DB (2005) Phase I clinical study of pertuzumab, a novel HER dimerization inhibitor, in patients with advanced cancer. J Clin Oncol 23: 2534-2543.

Agus DB, Sweeney CJ, Morris MJ, Mendelson DS, McNeel DG, Ahmann FR, Wang J, Derynck MK, Ng K, Lyons B, Allison DE, Kattan MW, Scher HI (2007) Efficacy and safety of single-agent pertuzumab (rhuMAb 2C4), a human epidermal growth factor receptor dimerization inhibitor, in castration-resistant prostate cancer after progression from taxane-based therapy. J Clin Oncol 25: 675-681.

Alfonso S, Díaz RM, de la Torre A, Santiesteban E, Aguirre F, Pérez K, Rodríguez JL, Barroso MC, Hernández AM, Toledo D, Gabri MR, Alonso DF, Viada C, Gómez RE, Pestana E, Suarez E, Vázquez AM, Perez R, Macías A (2007) 1E10 anti-idiotype vaccine in non-small cell lung cancer: experience in stage IIIb/IV patients. Cancer Biol Ther 6: $1847-1852$

Alfonso S, Valdes-Zayas A, Santiesteban ER, Flores YI, Areces F, Hernandez M, Viada CE, Mendoza IC, Guerra PP, Garcia E, Ortiz RA, de la Torre AV, Cepeda M, Perez K, Chong E, Hernandez AM, Toledo D, Gonzalez Z, Mazorra Z, Crombet T, Perez R, Vazquez AM, Macias AE (2014) A randomized, multicenter, placebo-controlled clinical trial of racotumomab-alum vaccine as switch maintenance therapy in advanced non-small cell lung cancer patients. Clin Cancer Res 20: 3660-3671.

Ansell SM, Lesokhin AM, Borrello I, Halwani A, Scott EC, Gutierrez M, Schuster SJ, Millenson MM, Cattry D, Freeman GJ, Rodig SJ, Chapuy B, Ligon AH, Zhu L, Grosso JF, Kim SY, Timmerman JM, Shipp MA, Armand P (2015) PD-1 blockade with nivolumab in relapsed or refractory Hodgkin's lymphoma. N Engl J Med 372: 311-319.

Armand P, Nagler A, Weller EA, Devine SM, Avigan DE, Chen Y-B, Kaminski MS, Holland HK, Winter JN, Mason JR, Fay JW, Rizzieri DA, Hosing CM, Ball ED, Uberti JP, Lazarus HM, Mapara MY, Gregory SA, Timmerman JM, Andorsky D, Or R, Waller EK, Rotem-Yehudar R, Gordon LI (2013) Disabling Immune tolerance by programmed death-1 blockade with pidilizumab after autologous hematopoietic stem-cell transplantation for diffuse large B-cell lymphoma: results of an International Phase II Trial. J Clin Oncol 31: 4199-4206.

Atzori F, Tabernero J, Cervantes A, Prudkin L, Andreu J, Rodriguez-Braun E, Domingo A, Guijarro J, Gamez C, Rodon J, Di Cosimo S, Brown H, Clark J, Hardwick JS, Beckman RA, Hanley WD, Hsu K, Calvo E, Rosello S, Langdon RB, Baselga J (2011) A phase I pharmacokinetic and pharmacodynamic study of dalotuzumab (MK-0646), an anti-insulin-like growth factor-1 receptor monoclonal antibody, in patients with advanced solid tumors. Clin Cancer Res 17: 6304-6312.

Azzopardi N, Dupuis-Girod S, Ternant D, Fargeton A-E, Ginon I, Faure F, Decullier E, Roux A, Carette M-F, Gilbert-Dussardier B, Hatron P-Y, Lacombe P, Leguy-Seguin V, Rivière S, Corre R, Bailly S, Paintaud G (2015) Dose-response relationship of bevacizumab in hereditary hemorrhagic telangiectasia. $m A b s$ 7: 630-637.

Azzopardi N, Lecomte T, Ternant D, Boisdron-Celle M, Piller F, Morel A, Gouilleux-Gruart V, Vignault-Desvignes C, Watier H, Gamelin E, Paintaud G (2011) Cetuximab pharmacokinetics influences progressionfree survival of metastatic colorectal cancer patients. Clin Cancer Res 17: 6329-6337.

Bartlett NL, Younes A, Carabasi MH, Forero A, Rosenblatt JD, Leonard JP, Bernstein SH, Bociek RG, Lorenz JM, Hart BW, Barton J (2008) A phase 1 multidose study of SGN-30 immunotherapy in patients with refractory or recurrent $\mathrm{CD} 30+$ hematologic malignancies. Blood 111: 1848-1854.

Baselga J, Pfister D, Cooper MR, Cohen R, Burtness B, Bos M, D'Andrea G, Seidman A, Norton L, Gunnett K, Falcey J, Anderson V, Waksal H, Mendelsohn J (2000) Phase I studies of anti-epidermal growth factor receptor chimeric antibody $\mathrm{C} 225$ alone and in combination with cisplatin. J Clin Oncol Off J Am Soc Clin Oncol 18: 904-914.

Baumgart DC, Targan SR, Dignass AU, Mayer L, Assche G, van, Hommes DW, Hanauer SB, Mahadevan U, Reinisch W, Plevy SE, Salzberg BA, Buchman AL, Mechkov GM, Krastev ZA, Lowder JN, Frankel MB, Sandborn WJ (2010) Prospective randomized open-label multicenter phase I/II dose escalation trial of visilizumab (HuM291) in severe steroid-refractory ulcerative colitis $\dagger$. Inflamm Bowel Dis 16: 620-629.

Bell-McGuinn KM, Matthews CM, Ho SN, Barve M, Gilbert L, Penson RT, Lengyel E, Palaparthy R, Gilder K, Vassos A, McAuliffe W, Weymer S,
Barton J, Schilder RJ (2011) A phase II, single-arm study of the anti- $\alpha 5 \beta 1$ integrin antibody volociximab as monotherapy in patients with platinumresistant advanced epithelial ovarian or primary peritoneal cancer. Gynecol Oncol 121: 273-279.

Bensinger W, Maziarz RT, Jagannath S, Spencer A, Durrant S, Becker PS, Ewald B, Bilic S, Rediske J, Baeck J, Stadtmauer EA (2012) A phase 1 study of lucatumumab, a fully human anti-CD40 antagonist monoclonal antibody administered intravenously to patients with relapsed or refractory multiple myeloma. Br J Haematol 159: 58-66.

Berger R, Rotem-Yehudar R, Slama G, Landes S, Kneller A, Leiba M, Koren-Michowitz M, Shimoni A, Nagler A (2008) Phase I safety and pharmacokinetic study of CT-011, a humanized antibody interacting with PD-1, in patients with advanced hematologic malignancies. Clin Cancer Res 14: 3044-3051.

Bishton M, Spencer A, Dickinson M, Ritchie D (2013) A single-arm, phase II study of the anti-Blys monoclonal antibody belimumab in symptomatic Waldenstrom macroglobulinemia. Clin Lymphoma Myeloma Leuk 13: 575-578.

Borghaei H, Paz-Ares L, Horn L, Spigel DR, Steins M, Ready NE, Chow LQ, Vokes EE, Felip E, Holgado E, Barlesi F, Kohlhäufl M, Arrieta O, Burgio MA, Fayette J, Lena H, Poddubskaya E, Gerber DE, Gettinger SN, Rudin CM, Rizvi N, Crinò L, Blumenschein GR, Antonia SJ, Dorange C, Harbison CT, Graf Finckenstein F, Brahmer JR (2015) Nivolumab versus docetaxel in advanced nonsquamous non-small-cell lung cancer. $\mathrm{N} \mathrm{Engl} \mathrm{J}$ Med 373: 1627-1639.

Brahmer J, Reckamp KL, Baas P, Crinò L, Eberhardt WEE, Poddubskaya E, Antonia S, Pluzanski A, Vokes EE, Holgado E, Waterhouse D, Ready N, Gainor J, Arén Frontera O, Havel L, Steins M, Garassino MC, Aerts JG, Domine M, Paz-Ares L, Reck M, Baudelet C, Harbison CT, Lestini B, Spigel DR (2015) Nivolumab versus docetaxel in advanced squamous-cell non-small-cell lung cancer. N Engl J Med 373: 123-135.

Brahmer JR, Drake CG, Wollner I, Powderly JD, Picus J, Sharfman WH, Stankevich E, Pons A, Salay TM, McMiller TL, Gilson MM, Wang C, Selby M, Taube JM, Anders R, Chen L, Korman AJ, Pardoll DM, Lowy I, Topalian SL (2010) Phase I study of single-agent anti-programmed death1 (MDX-1106) in refractory solid tumors: safety, clinical activity, pharmacodynamics, and immunologic correlates. J Clin Oncol 28: 3167-3175.

Byrd JC, Flynn JM, Kipps TJ, Boxer M, Kolibaba KS, Carlile DJ, FingerleRowson G, Tyson N, Hirata J, Sharman JP (2016) Randomized phase 2 study of obinutuzumab monotherapy in symptomatic, previously untreated chronic lymphocytic leukemia. Blood 127: 79-86.

Byrd JC, O’Brien S, Flinn IW, Kipps TJ, Weiss M, Rai K, Lin TS, Woodworth J, Wynne D, Reid J, Molina A, Leigh B, Harris S (2007) Phase 1 study of lumiliximab with detailed pharmacokinetic and pharmacodynamic measurements in patients with relapsed or refractory chronic lymphocytic leukemia. Clin Cancer Res 13: 4448-4455.

Camacho LH, Antonia S, Sosman J, Kirkwood JM, Gajewski TF, Redman B, Pavlov D, Bulanhagui C, Bozon VA, Gomez-Navarro J, Ribas A (2009) Phase I/II trial of tremelimumab in patients with metastatic melanoma. J Clin Oncol 27: 1075-1081.

Carpenter PA, Appelbaum FR, Corey L, Deeg HJ, Doney K, Gooley T, Krueger J, Martin P, Pavlovic S, Sanders J, Slattery J, Levitt D, Storb R, Woolfrey A, Anasetti C (2002) A humanized non-FcR-binding anti-CD3 antibody, visilizumab, for treatment of steroid-refractory acute graftversus-host disease. Blood 99: 2712-2719.

Carpenter PA, Lowder J, Johnston L, Frangoul H, Khoury H, Parker P, Jerome KR, McCune JS, Storer B, Martin P, Appelbaum F, Abonour R, Westervelt P, Anasetti C (2005) A phase II multicenter study of visilizumab, humanized anti-CD3 antibody, to treat steroid-refractory acute graft-versus-host disease. Biol Blood Marrow Transplant 11: 465-471.

Cartron G, De Guibert S, Dilhuydy M-S, Morschhauser F, Leblond V, Dupuis J, Mahe B, Bouabdallah R, Lei G, Wenger M, Wassner-Fritsch E, Hallek M (2014) Obinutuzumab (GA101) in relapsed/refractory chronic lymphocytic leukemia: final data from the phase $1 / 2$ GAUGUIN study. Blood 124: 2196-2202.

Cartron G, Hourcade-Potelleret F, Morschhauser F, Salles G, Wenger M, Truppel-Hartmann A, Carlile DJ (2016) Rationale for optimal obinutuzumab/GA101 dosing regimen in B-cell non-Hodgkin lymphoma. Haematologica 101: 226-234.

Carvajal RD, Wong MK, Thompson JA, Gordon MS, Lewis KD, Pavlick AC, Wolchok JD, Rojas PB, Schwartz JD, Bedikian AY (2014) A phase 2 
randomised study of ramucirumab (IMC-1121B) with or without dacarbazine in patients with metastatic melanoma. Eur J Cancer 50: 2099-2107.

Chiorean EG, Hurwitz HI, Cohen RB, Schwartz JD, Dalal RP, Fox FE, Gao L, Sweeney CJ (2015) Phase I study of every 2- or 3-week dosing of ramucirumab, a human immunoglobulin G1 monoclonal antibody targeting the vascular endothelial growth factor receptor- 2 in patients with advanced solid tumors. Ann Oncol 26: 1230-1237.

Chung KY, Gore I, Fong L, Venook A, Beck SB, Dorazio P, Criscitiello PJ, Healey DI, Huang B, Gomez-Navarro J, Saltz LB (2010) Phase II study of the anti-cytotoxic T-lymphocyte-associated antigen 4 monoclonal antibody, tremelimumab, in patients with refractory metastatic colorectal cancer. J Clin Oncol 28: 3485-3490.

Coiffier B, Radford J, Bosly A, Martinelli G, Barca G, Davies A, Decaudin D, Gallop-Evans E, Padmanabhan-Iyer S, Van Eygen K, Wu KL, Gupta, Lin TS, Goldstein N, Jewell RC, Winter P, Lisby S. 415 study investigators (2013) A multicentre, phase II trial of ofatumumab monotherapy in relapsed/progressive diffuse large B-cell lymphoma. Br J Haematol 163: 334-342.

Cunningham D, Humblet Y, Siena S, Khayat D, Bleiberg H, Santoro A, Bets D, Mueser M, Harstrick A, Verslype C, Chau I, Van Cutsem E (2004) Cetuximab monotherapy and cetuximab plus irinotecan in irinotecanrefractory metastatic colorectal cancer. $N$ Engl J Med 351: 337-345.

Czuczman MS, Fayad L, Delwail V, Cartron G, Jacobsen E, Kuliczkowski K, Link BK, Pinter-Brown L, Radford J, Hellmann A, Gallop-Evans E, DiRienzo CG, Goldstein N, Gupta I, Jewell RC, Lin TS, Lisby S, Schultz M, Russell CA, Hagenbeek A. 405 Study Investigators (2012) Ofatumumab monotherapy in rituximab-refractory follicular lymphoma: results from a multicenter study. Blood 119: 3698-3704.

De Bono JS, Bellmunt J, Attard G, Droz JP, Miller K, Flechon A, Sternberg C, Parker C, Zugmaier G, Hersberger-Gimenez V, Cockey L, Mason M, Graham J (2007) Open-label phase II study evaluating the efficacy and safety of two doses of pertuzumab in castrate chemotherapy-naive patients with hormone-refractory prostate cancer. J Clin Oncol 25: 257-262.

De Bono JS, Tolcher AW, Forero A, Vanhove GFA, Takimoto C, Bauer RJ, Hammond LA, Patnaik A, White ML, Shen S, Khazaeli MB, Rowinsky EK, LoBuglio AF (2004) ING-1, a monoclonal antibody targeting Ep-CAM in patients with advanced adenocarcinomas. Clin Cancer Res Off J Am Assoc Cancer Res 10: 7555-7565.

De Vita S, Quartuccio L, Seror R, Salvin S, Ravaud P, Fabris M, Nocturne G, Gandolfo S, Isola M, Mariette X (2015) Efficacy and safety of belimumab given for 12 months in primary Sjögren's syndrome: the BELISS openlabel phase II study. Rheumatology 54: 2249-2256kev257.

Delord J-P, Tabernero J, García-Carbonero R, Cervantes A, Gomez-Roca C, Bergé Y, Capdevila J, Paz-Ares L, Roda D, Delmar P, Oppenheim D, Brossard SS, Farzaneh F, Manenti L, Passioukov A, Ott MG, Soria J-C (2014) Open-label, multicentre expansion cohort to evaluate imgatuzumab in pre-treated patients with KRAS-mutant advanced colorectal carcinoma. Eur J Cancer 50: 496-505.

Dostalek M, Gardner I, Gurbaxani BM, Rose RH, Chetty M (2013) Pharmacokinetics, pharmacodynamics and physiologically-based pharmacokinetic modelling of monoclonal antibodies. Clin Pharmacokinet 52: 83-124.

Duffy A, Ulahannan S, Cao L, Rahma O, Makarova-Rusher O, Kleiner D, Fioravanti S, Walker M, Carey S, Yu Y, Venkatesan A, Turkbey B, Choyke P, Trepel J, Bollen K, Steinberg S, Figg W, Greten T (2015) A phase II study of TRC105 in patients with hepatocellular carcinoma who have progressed on sorafenib. United Eur Gastroenterol J 3: 453-461.

Duvic M, Pinter-Brown LC, Foss FM, Sokol L, Jorgensen JL, Challagundla P, Dwyer KM, Zhang X, Kurman MR, Ballerini R, Liu L, Kim YH (2015) Phase 1/2 study of mogamulizumab, a defucosylated anti-CCR4 antibody, in previously treated patients with cutaneous T-cell lymphoma. Blood 125: 1883-1889.

Duvic M, Reddy SA, Pinter-Brown L, Korman NJ, Zic J, Kennedy DA, Lorenz J, Sievers EL, Kim YH (2009) A phase II study of SGN-30 in cutaneous anaplastic large cell lymphoma and related lymphoproliferative disorders. Clin Cancer Res 15: 6217-6224.

Díaz A, Alfonso M, Alonso R, Saurez G, Troche M, Catalá M, Díaz RM, Pérez R, Vázquez AM (2003) Immune responses in breast cancer patients immunized with an anti-idiotype antibody mimicking NeuGc-containing gangliosides. Clin Immunol 107: 80-89.

D' Angelo SP, Mahoney MR, Van Tine BA, Adkins DR, Perdekamp MTG, Condy MM, Luke JJ, Hartley EW, Antonescu CR, Tap WD, Schwartz GK
(2015) Alliance A091103 a phase II study of the angiopoietin 1 and 2 peptibody trebananib for the treatment of angiosarcoma. Cancer Chemother Pharmacol 75: 629-638.

Eisenhauer EA, O'Dwyer PJ, Christian M, Humphrey JS (2000) Phase I clinical trial design in cancer drug development. J Clin Oncol Off J Am Soc Clin Oncol 18: 684-692.

Emu B, Luca D, Offutt C, Grogan JL, Rojkovich B, Williams MB, Tang MT, Xiao J, Lee JH, Davis JC (2012) Safety, pharmacokinetics, and biologic activity of pateclizumab, a novel monoclonal antibody targeting lymphotoxin $\alpha$ : results of a phase I randomized, placebo-controlled trial. Arthritis Res Ther 14: R6.

Fanale M, Assouline S, Kuruvilla J, Solal-Céligny P, Heo DS, Verhoef G, Corradini P, Abramson JS, Offner F, Engert A, Dyer MJS, Carreon D, Ewald B, Baeck J, Younes A, Freedman AS (2014) Phase IA/II, multicentre, open-label study of the CD40 antagonistic monoclonal antibody lucatumumab in adult patients with advanced non-Hodgkin or Hodgkin lymphoma. Br J Haematol 164: 258-265.

Forero-Torres A, de Vos S, Pohlman BL, Pashkevich M, Cronier DM, Dang NH, Carpenter SP, Allan BW, Nelson JG, Slapak CA, Smith MR, Link BK, Wooldridge JE, Ganjoo KN (2012) Results of a phase 1 study of AME-133v (LY2469298), an Fc-engineered humanized monoclonal antiCD20 antibody, in Fc RIIIa-genotyped patients with previously treated follicular lymphoma. Clin Cancer Res 18: 1395-1403.

Forero-Torres A, Shah J, Wood T, Posey J, Carlisle R, Copigneaux C, Luo FR, Wojtowicz-Praga S, Percent I, Saleh M (2010) Phase I trial of weekly tigatuzumab, an agonistic humanized monoclonal antibody targeting death receptor 5 (DR5). Cancer Biother Radiopharm 25: 13-19.

Fuchs CS, Tomasek J, Yong CJ, Dumitru F, Passalacqua R, Goswami C, Safran H, dos Santos LV, Aprile G, Ferry DR, Melichar B, Tehfe M, Topuzov E, Zalcberg JR, Chau I, Campbell W, Sivanandan C, Pikiel J, Koshiji M, Hsu Y, Liepa AM, Gao L, Schwartz JD, Tabernero J. REGARD Trial Investigators (2014) Ramucirumab monotherapy for previously treated advanced gastric or gastro-oesophageal junction adenocarcinoma (REGARD): an international, randomised, multicentre, placebocontrolled, phase 3 trial. The Lancet 383: 31-39.

Furie R, Stohl W, Ginzler EM, Becker M, Mishra N, Chatham WW, Merrill JT, Weinstein A, McCune WJ, Zhong J, Cai W, Freimuth W, Study Group B (2008) Biologic activity and safety of belimumab, a neutralizing anti-B-lymphocyte stimulator (BLyS) monoclonal antibody: a phase I trial in patients with systemic lupus erythematosus. Arthritis Res Ther 10: R109.

Furtado M, Dyer MJS, Johnson R, Berrow M, Rule S (2014) Ofatumumab monotherapy in relapsed/refractory mantle cell lymphoma - a phase II trial. Br J Haematol 165: 575-578.

Ganjoo KN, de Vos S, Pohlman BL, Flinn IW, Forero-Torres A, Enas NH, Cronier DM, Dang NH, Foon KA, Carpenter SP, Slapak CA, Link BK, Smith MR, Mapara MY, Wooldridge JE (2015) Phase 1/2 study of ocaratuzumab, an Fc-engineered humanized anti-CD20 monoclonal antibody, in low-affinity Fc $\gamma$ RIIIa patients with previously treated follicular lymphoma. Leuk Lymphoma 56: 42-48.

Garcia JA, Hudes GR, Choueiri TK, Stadler WM, Wood LS, Gurtler J, Bhatia S, Joshi A, Hozak RR, Xu Y, Schwartz JD, Thompson JA (2014) A phase 2, single-arm study of ramucirumab in patients with metastatic renal cell carcinoma with disease progression on or intolerance to tyrosine kinase inhibitor therapy: ramucirumab in metastatic RCC. Cancer 120: 1647-1655.

Gardiner D, Lalezari J, Lawitz E, DiMicco M, Ghalib R, Reddy KR, Chang K-M, Sulkowski M, O'Marro S, Anderson J, He B, Kansra V, McPhee F, Wind-Rotolo M, Grasela D, Selby M, Korman AJ, Lowy I (2013) A randomized, double-blind, placebo-controlled assessment of BMS-936558, a fully human monoclonal antibody to programmed death-1 (PD-1), in patients with chronic hepatitis C virus infection. PLoS One 8: e63818.

Genovese MC, Greenwald M, Cho C-S, Berman A, Jin L, Cameron GS, Benichou O, Xie L, Braun D, Berclaz P-Y, Banerjee S (2014) A phase II randomized study of subcutaneous ixekizumab, an anti-interleukin-17 monoclonal antibody, in rheumatoid arthritis patients who were naive to biologic agents or had an inadequate response to tumor necrosis factor inhibitors: ixekizumab in biologics-naive and TNF inadequate responder RA patients. Arthritis Rheumatol 66: 1693-1704.

Genovese MC, Kaine JL, Lowenstein MB, Del Giudice J, Baldassare A, Schechtman J, Fudman E, Kohen M, Gujrathi S, Trapp RG, Sweiss NJ, Spaniolo G, Dummer W. ACTION Study Group (2008) Ocrelizumab, a humanized anti-CD20 monoclonal antibody, in the treatment of patients 
with rheumatoid arthritis: a phase I/II randomized, blinded, placebocontrolled, dose-ranging study. Arthritis Rheum 58: 2652-2661.

Genovese MC, Van den Bosch F, Roberson SA, Bojin S, Biagini IM, Ryan P, Sloan-Lancaster J (2010) LY2439821, a humanized anti-interleukin-17 monoclonal antibody, in the treatment of patients with rheumatoid arthritis: a phase I randomized, double-blind, placebo-controlled, proofof-concept study. Arthritis Rheum 62: 929-939.

Gianni L, Llado A, Bianchi G, Cortes J, Kellokumpu-Lehtinen P-L, Cameron DA, Miles D, Salvagni S, Wardley A, Goeminne J-C, Hersberger V, Baselga J (2010) Open-label, phase II, multicenter, randomized study of the efficacy and safety of two dose levels of pertuzumab, a human epidermal growth factor receptor 2 dimerization inhibitor, in patients with human epidermal growth factor receptor 2-negative metastatic breast cancer. J Clin Oncol 28 : 1131-1137.

Goel S, Bauer RJ, Desai K, Bulgaru A, Iqbal T, Strachan B-K, Kim G, Kaubisch A, Vanhove GF, Goldberg G, Mani S (2007) Pharmacokinetic and safety study of subcutaneously administered weekly ING-1, a human engineeredTM monoclonal antibody targeting human EpCAM, in patients with advanced solid tumors. Ann Oncol 18: 1704-1707.

Gordon KB, Leonardi CL, Lebwohl M, Blauvelt A, Cameron GS, Braun D, Erickson J, Heffernan M (2014) A 52-week, open-label study of the efficacy and safety of ixekizumab, an anti-interleukin-17A monoclonal antibody, in patients with chronic plaque psoriasis. J Am Acad Dermatol 71: $1176-1182$.

Gordon MS, Margolin K, Talpaz M, Sledge Jr GW, Holmgren E, Benjamin R, Stalter S, Shak S, Adelman D (2001) Phase I safety and pharmacokinetic study of recombinant human anti-vascular endothelial growth factor in patients with advanced cancer. J Clin Oncol Off J Am Soc Clin Oncol 19: 843-850.

Gordon MS, Matei D, Aghajanian C, Matulonis UA, Brewer M, Fleming GF, Hainsworth JD, Garcia AA, Pegram MD, Schilder RJ, Cohn DE, Roman L, Derynck MK, Ng K, Lyons B, Allison DE, Eberhard DA, Pham TQ, Dere RC, Karlan BY (2006) Clinical activity of pertuzumab (rhuMAb 2C4), a HER dimerization inhibitor, in advanced ovarian cancer: potential predictive relationship with tumor HER2 activation status. J Clin Oncol 24: 4324-4332.

Gordon MS, Sweeney CJ, Mendelson DS, Eckhardt SG, Anderson A, Beaupre DM, Branstetter D, Burgess TL, Coxon A, Deng H, Kaplan-Lefko P, Leitch IM, Oliner KS, Yan L, Zhu M, Gore L (2010) Safety, pharmacokinetics, and pharmacodynamics of AMG 102, a fully human hepatocyte growth factor-neutralizing monoclonal antibody, in a first-inhuman study of patients with advanced solid tumors. Clin Cancer Res 16: 699-710.

Greco FA, Bonomi P, Crawford J, Kelly K, Oh Y, Halpern W, Lo L, Gallant G, Klein J (2008) Phase 2 study of mapatumumab, a fully human agonistic monoclonal antibody which targets and activates the TRAIL receptor-1, in patients with advanced non-small cell lung cancer. Lung Cancer 61: $82-90$.

Hagenbeek A, Gadeberg O, Johnson P, Moller Pedersen L, Walewski J, Hellmann A, Link BK, Robak T, Wojtukiewicz M, Pfreundschuh M, Kneba M, Engert A, Sonneveld P, Flensburg M, Petersen J, Losic N, Radford J (2008) First clinical use of ofatumumab, a novel fully human anti-CD20 monoclonal antibody in relapsed or refractory follicular lymphoma: results of a phase 1/2 trial. Blood 111: 5486-5495.

Hamanishi J, Mandai M, Ikeda T, Minami M, Kawaguchi A, Murayama T, Kanai M, Mori Y, Matsumoto S, Chikuma S, Matsumura N, Abiko K, Baba T, Yamaguchi K, Ueda A, Hosoe Y, Morita S, Yokode M, Shimizu A, Honjo T, Konishi I (2015) Safety and antitumor activity of anti-PD-1 antibody, nivolumab, in patients with platinum-resistant ovarian cancer. J Clin Oncol 33: 4015-4022.

Heldin C-H, Rubin K, Pietras K, Östman A (2004) High interstitial fluid pressure - an obstacle in cancer therapy. Nat Rev Cancer 4: 806-813.

Herbst RS, Davies AM, Natale RB, Dang TP, Schiller JH, Garland LL, Miller VA, Mendelson D, Van den Abbeele AD, Melenevsky Y, de Vries DJ, Eberhard DA, Lyons B, Lutzker SG, Johnson BE (2007) Efficacy and safety of single-agent pertuzumab, a human epidermal receptor dimerization inhibitor, in patients with non small cell lung cancer. Clin Cancer Res 13: 6175-6181.

Herbst RS, Hong D, Chap L, Kurzrock R, Jackson E, Silverman JM, Rasmussen E, Sun Y-N, Zhong D, Hwang YC, Evelhoch JL, Oliner JD, Le N, Rosen LS (2009) Safety, pharmacokinetics, and antitumor activity of AMG 386, a selective angiopoietin inhibitor, in adult patients with advanced solid tumors. J Clin Oncol 27: 3557-3565.
Hofheinz R-D, Al-Batran S-E, Hartmann F, Hartung G, Jäger D, Renner C, Tanswell P, Kunz U, Amelsberg A, Kuthan H, Stehle G (2003) Stromal antigen targeting by a humanised monoclonal antibody: an early phase II trial of sibrotuzumab in patients with metastatic colorectal cancer. Oncol Res Treat 26: 44-48.

Ishida T, Joh T, Uike N, Yamamoto K, Utsunomiya A, Yoshida S, Saburi Y, Miyamoto T, Takemoto S, Suzushima H, Tsukasaki K, Nosaka K, Fujiwara $\mathrm{H}$, Ishitsuka $\mathrm{K}$, Inagaki $\mathrm{H}$, Ogura $\mathrm{M}$, Akinaga $\mathrm{S}$, Tomonaga $\mathrm{M}$, Tobinai K, Ueda R (2012) Defucosylated anti-CCR4 monoclonal antibody (KW-0761) for relapsed adult T-cell leukemia-lymphoma: a multicenter phase II study. J Clin Oncol 30: 837-842.

Janne PA, Kim G, Shaw AT, Sridhara R, Pazdur R, McKee AE (2016) Dose finding of small-molecule oncology drugs: optimization throughout the development life cycle. Clin Cancer Res 22: 2613-2617.

Jardim DL, Hess KR, LoRusso P, Kurzrock R, Hong DS (2014) Predictive value of phase I trials for safety in later trials and final approved dose: analysis of 61 approved cancer drugs. Clin Cancer Res 20: 281-288.

Kappos L, Li D, Calabresi PA, O’Connor P, Bar-Or A, Barkhof F, Yin M, Leppert D, Glanzman R, Tinbergen J, Hauser SL (2011) Ocrelizumab in relapsing-remitting multiple sclerosis: a phase 2 , randomised, placebocontrolled, multicentre trial. Lancet 378: 1779-1787.

Kennedy WP, Simon JA, Offutt C, Horn P, Herman A, Townsend MJ, Tang MT, Grogan JL, Hsieh F, Davis JC (2014) Efficacy and safety of pateclizumab (anti-lymphotoxin- $\alpha$ ) compared to adalimumab in rheumatoid arthritis: a head-to-head phase 2 randomized controlled study (The ALTARA Study). Arthritis Res Ther 16: 467.

Kirkwood JM, Lorigan P, Hersey P, Hauschild A, Robert C, McDermott D, Marshall MA, Gomez-Navarro J, Liang JQ, Bulanhagui CA (2010) Phase II trial of tremelimumab $(\mathrm{CP}-675,206)$ in patients with advanced refractory or relapsed melanoma. Clin Cancer Res 16: 1042-1048.

Korde N, Carlsten M, Lee M-J, Minter A, Tan E, Kwok M, Manasanch E, Bhutani M, Tageja N, Roschewski M, Zingone A, Costello R, Mulquin M, Zuchlinski D, Maric I, Calvo KR, Braylan R, Tembhare P, Yuan C, Stetler-Stevenson M, Trepel J, Childs R, Landgren O (2014) A phase II trial of pan-KIR2D blockade with IPH2101 in smoldering multiple myeloma. Haematologica 99: e81-e83.

Krug LM, Milton DT, Jungbluth AA, Chen L-C, Quaia E, Pandit-Taskar N, Nagel A, Jones J, Kris MG, Finn R, Smith-Jones P, Scott AM, Old L, Divgi C (2007) Targeting Lewis Y (Le y) in small cell lung cancer with a humanized monoclonal antibody, hu3S193: a pilot trial testing two dose levels. J Thorac Oncol 2: 947-952.

Kurose K, Ohue Y, Wada H, Iida S, Ishida T, Kojima TT, Suzuki S, Isobe M, Funakoshi T, Kakimi K, Nishikawa H, Udono H, Oka M, Ueda R, Nakayama E (2015) Phase Ia study of FoxP3 + CD4 Treg depletion by infusion of a humanized anti-CCR4 antibody, KW-0761, in cancer patients. Clin Cancer Res 21: 4327-4336.

Le Tourneau C, Lee JJ, Siu LL (2009) Dose escalation methods in phase I cancer clinical trials. J Natl Cancer Inst 101: 708-720.

Leonardi C, Matheson R, Zachariae C, Cameron G, Li L, Edson-Heredia E, Braun D, Banerjee S (2012) Anti-interleukin-17 monoclonal antibody ixekizumab in chronic plaque psoriasis. N Engl J Med 366: 1190-1199.

Marschner N, Rüttinger D, Zugmaier G, Nemere G, Lehmann J, Obrist P, Baeuerle PA, Wolf A, Schmidt M, Abrahamsson P-A, Reinhardt C, Heidenreich A (2010) Phase II study of the human anti-epithelial cell adhesion molecule antibody adecatumumab in prostate cancer patients with increasing serum levels of prostate-specific antigen after radical prostatectomy. Urol Int 85: 386-395.

Maubec E, Petrow P, Scheer-Senyarich I, Duvillard P, Lacroix L, Gelly J, Certain A, Duval X, Crickx B, Buffard V, Basset-Seguin N, Saez P, DuvalModeste A-B, Adamski H, Mansard S, Grange F, Dompmartin A, Faivre S, Mentre F, Avril M-F (2011) Phase II study of cetuximab as first-line single-drug therapy in patients with unresectable squamous cell carcinoma of the skin. J Clin Oncol 29: 3419-3426.

Mayer CL, Xie L, Bandekar R, Qi M, van de Velde H, Reddy M, Qin X, Davis HM, Puchalski TA (2015) Dose selection of siltuximab for multicentric Castleman's disease. Cancer Chemother Pharmacol 75: 10371045.

Meulendijks D, Jacob W, Martinez-Garcia M, Taus A, Lolkema MP, Voest EE, Langenberg MHG, Fleitas Kanonnikoff T, Cervantes A, De Jonge MJ, Sleijfer S, Soerensen MM, Thomas M, Ceppi M, Meneses-Lorente G, James I, Adessi C, Michielin F, Abiraj K, Bossenmaier B, Schellens JHM, Weisser M, Lassen UN (2016) First-in-human phase I study of lumretuzumab, a glycoengineered humanized anti-HER3 monoclonal 
antibody, in patients with metastatic or advanced HER3-positive solid tumors. Clin Cancer Res Off J Am Assoc Cancer Res 22: 877-885.

Moore KN, Sill MW, Tenney ME, Darus CJ, Griffin D, Werner TL, Rose PG, Behrens R (2015) A phase II trial of trebananib (AMG 386; IND\#111071), a selective angiopoietin $1 / 2$ neutralizing peptibody, in patients with persistent/recurrent carcinoma of the endometrium: An NRG/ Gynecologic Oncology Group trial. Gynecol Oncol 138: 513-518.

Morschhauser FA, Cartron G, Thieblemont C, Solal-Celigny P, Haioun C, Bouabdallah R, Feugier P, Bouabdallah K, Asikanius E, Lei G, Wenger M, Wassner-Fritsch E, Salles GA (2013) Obinutuzumab (GA101) monotherapy in relapsed/refractory diffuse large B-cell lymphoma or mantle-cell lymphoma: results from the phase II GAUGUIN study. J Clin Oncol 31: 2912-2919.

Motzer RJ, Escudier B, McDermott DF, George S, Hammers HJ, Srinivas S, Tykodi SS, Sosman JA, Procopio G, Plimack ER, Castellano D, Choueiri TK, Gurney H, Donskov F, Bono P, Wagstaff J, Gauler TC, Ueda T, Tomita Y, Schutz FA, Kollmannsberger C, Larkin J, Ravaud A, Simon JS, Xu L-A, Waxman IM, Sharma P (2015a) Nivolumab versus everolimus in advanced renal-cell carcinoma. N Engl J Med 373: 1803-1813.

Motzer RJ, Rini BI, McDermott DF, Redman BG, Kuzel TM, Harrison MR, Vaishampayan UN, Drabkin HA, George S, Logan TF, Margolin KA, Plimack ER, Lambert AM, Waxman IM, Hammers HJ (2015b) Nivolumab for metastatic renal cell carcinoma: results of a randomized phase II trial. J Clin Oncol 33: 1430-1437.

Mullamitha SA, Ton NC, Parker GJM, Jackson A, Julyan PJ, Roberts C, Buonaccorsi GA, Watson Y, Davies K, Cheung S, Hope L, Valle JW, Radford JA, Lawrance J, Saunders MP, Munteanu MC, Nakada MT, Nemeth JA, Davis HM, Jiao Q, Prabhakar U, Lang Z, Corringham RE, Beckman RA, Jayson GC. in association with the Biotherapy Development Association (2007) Phase I evaluation of a fully human anti- v integrin monoclonal antibody (CNTO 95) in patients with advanced solid tumors. Clin Cancer Res 13: 2128-2135.

Neal JW, Heist RS, Fidias P, Temel JS, Huberman M, Marcoux JP, Muzikansky A, Lynch TJ, Sequist LV (2010) Cetuximab monotherapy in patients with advanced non-small cell lung cancer after prior epidermal growth factor receptor tyrosine kinase inhibitor therapy. J Thorac Oncol 5: 1855-1858.

Nelson AL, Dhimolea E, Reichert JM (2010) Development trends for human monoclonal antibody therapeutics. Nat Rev Drug Discov 9: 767-774.

Neninger E, Diaz RM, de la Torre A, Rives R, Diaz A, Saurez G, Gabri MR, Alonso DF, Wilkinson B, Alfonso AM, Combet T, Perez R, Vázquez AM (2007) Active immunotherapy with 1E10 anti-idiotype vaccine in patients with small cell lung cancer: report of a phase I trial. Cancer Biol Ther 6: $145-150$.

Norman DJ, Vincenti F, de Mattos AM, Barry JM, Levitt DJ, Wedel NI, Maia M, Light SE (2000) Phase I trial of HuM291, a humanized anti-CD3 antibody, in patients receiving renal allografts from living donors. Transplantation 70: 1707-1712.

Oberneder R, Weckermann D, Ebner B, Quadt C, Kirchinger P, Raum T, Locher M, Prang N, Baeuerle PA, Leo E (2006) A phase I study with adecatumumab, a human antibody directed against epithelial cell adhesion molecule, in hormone refractory prostate cancer patients. Eur J Cancer 42: 2530-2538.

Ogita S, Tejwani S, Heilbrun L, Fontana J, Heath E, Freeman S, Smith D, Baranowski K, Vaishampayan U (2012) Pilot phase II trial of bevacizumab monotherapy in nonmetastatic castrate-resistant prostate cancer. ISRN Oncol 2012: 1-7.

O’Day S, Pavlick A, Loquai C, Lawson D, Gutzmer R, Richards J, Schadendorf D, Thompson JA, Gonzalez R, Trefzer U, Mohr P, Ottensmeier C, Chao D, Zhong B, de Boer CJ, Uhlar C, Marshall D, Gore ME, Lang Z, Hait W, Ho P (2011) A randomised, phase II study of intetumumab, an anti- $\alpha \mathrm{v}$-integrin $\mathrm{mAb}$, alone and with dacarbazine in stage IV melanoma. Br J Cancer 105: 346-352.

Österborg A, Udvardy M, Zaritskey A, Andersson P-O, Grosicki S, Mazur G, Kaplan P, Steurer M, Schuh A, Montillo M, Kryachok I, Middeke JM, Kulyaba Y, Rekhtman G, Gorczyca M, Daly S, Chang C-N, Lisby S, Gupta I (2016) Phase III, randomized study of ofatumumab versus physicians' choice of therapy and standard versus extended-length ofatumumab in patients with bulky fludarabine-refractory chronic lymphocytic leukemia. Leuk Lymphoma 57: 2037-2046.

Parulekar WR, Eisenhauer EA (2004) Phase I trial design for solid tumor studies of targeted, non-cytotoxic agents: theory and practice. $J$ Natl Cancer Inst 96: 990-997.
Paz-Ares LG, Gomez-Roca C, Delord J-P, Cervantes A, Markman B, Corral J, Soria J-C, Berge Y, Roda D, Russell-Yarde F, Hollingsworth S, Baselga J, Umana P, Manenti L, Tabernero J (2011) Phase I Pharmacokinetic and Pharmacodynamic Dose-Escalation Study of RG7160 (GA201), the first glycoengineered monoclonal antibody against the epidermal growth factor receptor, in patients with advanced solid tumors. J Clin Oncol 29: 3783-3790.

Penson RT, Moore KM, Fleming GF, Braly P, Schimp V, Nguyen H, Matulonis UA, Banerjee S, Haluska P, Gore M, Bodurka DC, Hozak RR, Joshi A, Xu Y, Schwartz JD, McGuire WP (2014) A phase II study of ramucirumab (IMC-1121B) in the treatment of persistent or recurrent epithelial ovarian, fallopian tube or primary peritoneal carcinoma. Gynecol Oncol 134: 478-485.

Pessino A, Artale S, Sciallero S, Guglielmi A, Fornarini G, Andreotti IC, Mammoliti S, Comandini D, Caprioni F, Bennicelli E, Andretta V, Siena S, Sobrero A (2007) First-line single-agent cetuximab in patients with advanced colorectal cancer. Ann Oncol 19: 711-716.

Plevy S, Salzberg B, Van Assche G, Regueiro M, Hommes D, Sandborn W, Hanauer S, Targan S, Mayer L, Mahadevan U, Frankel M, Lowder J (2007) A phase I study of visilizumab, a humanized anti-CD3 monoclonal antibody, in severe steroid-refractory ulcerative colitis. Gastroenterology 133: $1414-1422$.

Plummer R, Attard G, Pacey S, Li L, Razak A, Perrett R, Barrett M, Judson I, Kaye S, Fox NL, Halpern W, Corey A, Calvert H, de Bono J (2007) Phase 1 and pharmacokinetic study of lexatumumab in patients with advanced cancers. Clin Cancer Res 13: 6187-6194.

Ralph C, Elkord E, Burt DJ, O'Dwyer JF, Austin EB, Stern PL, Hawkins RE, Thistlethwaite FC (2010) Modulation of lymphocyte regulation for cancer therapy: a phase II trial of tremelimumab in advanced gastric and esophageal adenocarcinoma. Clin Cancer Res 16: 1662-1672.

Reidy-Lagunes DL, Vakiani E, Segal MF, Hollywood EM, Tang LH, Solit DB, Pietanza MC, Capanu M, Saltz LB (2012) A phase 2 study of the insulinlike growth factor-1 receptor inhibitor MK-0646 in patients with metastatic, well-differentiated neuroendocrine tumors. Cancer 118: $4795-4800$.

Ribas A (2005) Antitumor activity in melanoma and anti-self responses in a phase I trial with the anti-cytotoxic T lymphocyte-associated antigen 4 monoclonal antibody CP-675,206. J Clin Oncol 23: 8968-8977.

Ricart AD, Tolcher AW, Liu G, Holen K, Schwartz G, Albertini M, Weiss G, Yazji S, Ng C, Wilding G (2008) Volociximab, a chimeric monoclonal antibody that specifically binds 51 integrin: a phase I, pharmacokinetic, and biological correlative study. Clin Cancer Res 14: 7924-7929.

Rizvi NA, Mazières J, Planchard D, Stinchcombe TE, Dy GK, Antonia SJ, Horn L, Lena H, Minenza E, Mennecier B, Otterson GA, Campos LT, Gandara DR, Levy BP, Nair SG, Zalcman G, Wolf J, Souquet P-J, Baldini E, Cappuzzo F, Chouaid C, Dowlati A, Sanborn R, Lopez-Chavez A, Grohe C, Huber RM, Harbison CT, Baudelet C, Lestini BJ, Ramalingam SS (2015) Activity and safety of nivolumab, an anti-PD-1 immune checkpoint inhibitor, for patients with advanced, refractory squamous non-small-cell lung cancer (CheckMate 063): a phase 2, single-arm trial. Lancet Oncol 16: $257-265$.

Robert C, Long GV, Brady B, Dutriaux C, Maio M, Mortier L, Hassel JC, Rutkowski P, McNeil C, Kalinka-Warzocha E, Savage KJ, Hernberg MM, Lebbé C, Charles J, Mihalcioiu C, Chiarion-Sileni V, Mauch C, Cognetti F, Arance A, Schmidt H, Schadendorf D, Gogas H, Lundgren-Eriksson L, Horak C, Sharkey B, Waxman IM, Atkinson V, Ascierto PA (2015) Nivolumab in previously untreated melanoma without BRAF mutation. N Engl J Med 372: 320-330.

Rosen LS, Hurwitz HI, Wong MK, Goldman J, Mendelson DS, Figg WD, Spencer S, Adams BJ, Alvarez D, Seon BK, Theuer CP, Leigh BR, Gordon MS (2012) A phase I first-in-human study of TRC105 (anti-endoglin antibody) in patients with advanced cancer. Clin Cancer Res 18: $4820-4829$.

Sachs JR, Mayawala K, Gadamsetty S, Kang SP, de Alwis DP (2016) Optimal dosing for targeted therapies in oncology: drug development cases leading by example. Clin Cancer Res 22: 1318-1324.

Salles G, Morschhauser F, Lamy T, Milpied N, Thieblemont C, Tilly H, Bieska G, Asikanius E, Carlile D, Birkett J, Pisa P, Cartron G (2012) Phase 1 study results of the type II glycoengineered humanized anti-CD20 monoclonal antibody obinutuzumab (GA101) in B-cell lymphoma patients. Blood 119: 5126-5132.

Salles GA, Morschhauser F, Solal-Celigny P, Thieblemont C, Lamy T, Tilly H, Gyan E, Lei G, Wenger M, Wassner-Fritsch E, Cartron G (2013) 
Obinutuzumab (GA101) in patients with relapsed/refractory indolent non-Hodgkin lymphoma: results from the phase II GAUGUIN study J Clin Oncol 31: 2920-2926.

Sandborn WJ, Colombel JF, Frankel M, Hommes D, Lowder JN, Mayer L, Plevy S, Stokkers P, Travis S, Van Assche G, Baumgart DC, Targan SR (2010) Anti-CD3 antibody visilizumab is not effective in patients with intravenous corticosteroid-refractory ulcerative colitis. Gut 59: 1485-1492.

Sangro B, Gomez-Martin C, de la Mata M, Iñarrairaegui M, Garralda E, Barrera P, Riezu-Boj JI, Larrea E, Alfaro C, Sarobe P, Lasarte JJ, Pérez-Gracia JL, Melero I, Prieto J (2013) A clinical trial of CTLA-4 blockade with tremelimumab in patients with hepatocellular carcinoma and chronic hepatitis C. J Hepatol 59: 81-88.

Schmidt M, Scheulen ME, Dittrich C, Obrist P, Marschner N, Dirix L, Schmidt M, Ruttinger D, Schuler M, Reinhardt C, Awada A (2010) An open-label, randomized phase II study of adecatumumab, a fully human anti-EpCAM antibody, as monotherapy in patients with metastatic breast cancer. Ann Oncol 21: 275-282.

Schuster C, Eikesdal HP, Puntervoll H, Geisler J, Geisler S, Heinrich D, Molven A, Lønning PE, Akslen LA, Straume O (2012) Clinical efficacy and safety of bevacizumab monotherapy in patients with metastatic melanoma: predictive importance of induced early hypertension. PLoS One 7: e38364.

Schöffski P, Garcia JA, Stadler WM, Gil T, Jonasch E, Tagawa ST, Smitt M, Yang X, Oliner KS, Anderson A, Zhu M, Kabbinavar F (2011) A phase II study of the efficacy and safety of AMG 102 in patients with metastatic renal cell carcinoma: efficacy and safety of AMG 102 in metastatic RCC. BJU Int 108: 679-686.

Scott AM, Lee F-T, Tebbutt N, Herbertson R, Gill SS, Liu Z, Skrinos E, Murone C, Saunder TH, Chappell B, Papenfuss AT, Poon AMT, Hopkins W, Smyth FE, MacGregor D, Cher LM, Jungbluth AA, Ritter G, Brechbiel MW, Murphy R, Burgess AW, Hoffman EW, Johns TG, Old LJ (2007) A phase I clinical trial with monoclonal antibody ch806 targeting transitional state and mutant epidermal growth factor receptors. Proc Natl Acad Sci USA 104: 4071-4076.

Scott AM, Wiseman G, Welt S, Adjei A, Lee F-T, Hopkins W, Divgi CR, Hanson LH, Mitchell P, Gansen DN, Larson SM, Ingle JN, Hoffman EW, Tanswell P, Ritter G, Cohen LS, Bette P, Arvay L, Amelsberg A, Vlock D, Rettig WJ, Old LJ (2003) A Phase I dose-escalation study of sibrotuzumab in patients with advanced or metastatic fibroblast activation proteinpositive cancer. Clin Cancer Res Off J Am Assoc Cancer Res 9: 1639-1647.

Segelov E, Thavaneswaran S, Waring PM, Desai J, Robledo KP, Gebski VJ, Elez E, Nott LM, Karapetis CS, Lunke S, Chantrill LA, Pavlakis N, Khasraw M, Underhill C, Ciardiello F, Jefford M, Wasan H, Haydon A, Price TJ, van Hazel G, Wilson K, Simes J, Shapiro JD (2016) Response to cetuximab with or without irinotecan in patients with refractory metastatic colorectal cancer harboring the KRAS G13D mutation: Australasian Gastro-Intestinal Trials Group ICECREAM Study. J Clin Oncol 34: 2258-2264.

Sehn LH, Goy A, Offner FC, Martinelli G, Caballero MD, Gadeberg O, Baetz T, Zelenetz AD, Gaidano G, Fayad LE, Buckstein R, Friedberg JW, Crump M, Jaksic B, Zinzani PL, Padmanabhan Iyer S, Sahin D, Chai A, Fingerle-Rowson G, Press OW (2015) Randomized phase II trial comparing obinutuzumab (GA101) with rituximab in patients with relapsed CD20 + indolent B-cell non-Hodgkinlymphoma: final analysis of the GAUSS study. J Clin Oncol 33: 3467-3474.

Seiden MV, Burris HA, Matulonis U, Hall JB, Armstrong DK, Speyer J, Weber JDA, Muggia F (2007) A phase II trial of EMD72000 (matuzumab), a humanized anti-EGFR monoclonal antibody, in patients with platinumresistant ovarian and primary peritoneal malignancies. Gynecol Oncol 104 727-731.

Spratlin JL, Cohen RB, Eadens M, Gore L, Camidge DR, Diab S, Leong S, O’Bryant C, Chow LQM, Serkova NJ, Meropol NJ, Lewis NL, Chiorean EG, Fox F, Youssoufian H, Rowinsky EK, Eckhardt SG (2010) Phase I pharmacologic and biologic study of ramucirumab (IMC-1121B), a fully human immunoglobulin G1 monoclonal antibody targeting the vascular endothelial growth factor receptor-2. J Clin Oncol 28: 780-787.

Stevenson JP, Kindler HL, Papasavvas E, Sun J, Jacobs-Small M, Hull J, Schwed D, Ranganathan A, Newick K, Heitjan DF, Langer CJ, McPherson JM, Montaner LJ, Albelda SM (2013) Immunological effects of the TGF $\beta$-blocking antibody GC1008 in malignant pleural mesothelioma patients. OncoImmunology 2: e26218.

Strosberg JR, Chan JA, Ryan DP, Meyerhardt JA, Fuchs CS, Abrams T, Regan E, Brady R, Weber J, Campos T, Kvols LK, Kulke MH (2013) A multi-institutional, phase II open-label study of ganitumab (AMG 479) in advanced carcinoid and pancreatic neuroendocrine tumors. Endocr Relat Cancer 20: 383-390.

Sweis RF, Drazer MW, Ratain MJ (2016) Analysis of impact of post-treatment biopsies in phase I clinical trials. J Clin Oncol Off J Am Soc Clin Oncol 34: 369-374.

Tabernero J, Ciardiello F, Rivera F, Rodriguez-Braun E, Ramos FJ, Martinelli E, Vega-Villegas ME, Rosello S, Liebscher S, Kisker O, Macarulla T, Baselga J, Cervantes A (2010) Cetuximab administered once every second week to patients with metastatic colorectal cancer: a two-part pharmacokinetic/pharmacodynamic phase I dose-escalation study. Ann Oncol 21: 1537-1545.

Tabrizi M, Bornstein GG, Suria H (2010) Biodistribution mechanisms of therapeutic monoclonal antibodies in health and disease. AAPS J 12: 33-43.

Tap WD, Demetri G, Barnette P, Desai J, Kavan P, Tozer R, Benedetto PW, Friberg G, Deng H, McCaffery I, Leitch I, Badola S, Chang S, Zhu M, Tolcher A (2012) Phase II study of ganitumab, a fully human anti-type-1 insulin-like growth factor receptor antibody, in patients with metastatic Ewing family tumors or desmoplastic small round cell tumors. J Clin Oncol 30: 1849-1856.

Taylor PC, Quattrocchi E, Mallett S, Kurrasch R, Petersen J, Chang DJ (2011) Ofatumumab, a fully human anti-CD20 monoclonal antibody, in biological-naive, rheumatoid arthritis patients with an inadequate response to methotrexate: a randomised, double-blind, placebo-controlled clinical trial. Ann Rheum Dis 70: 2119-2125.

Tibbitts J, Canter D, Graff R, Smith A, Khawli LA (2016) Key factors influencing ADME properties of therapeutic proteins: A need for ADME characterization in drug discovery and development. mAbs 8: 229-245.

Tolcher AW, Sarantopoulos J, Patnaik A, Papadopoulos K, Lin C-C, Rodon J, Murphy B, Roth B, McCaffery I, Gorski KS, Kaiser B, Zhu M, Deng H, Friberg G, Puzanov I (2009) Phase I, pharmacokinetic, and pharmacodynamic study of AMG 479, a fully human monoclonal antibody to insulin-like growth factor receptor 1. J Clin Oncol 27: $5800-5807$.

Tosi D, Laghzali Y, Vinches M, Alexandre M, Homicsko K, Fasolo A, Del Conte G, Durigova A, Hayaoui N, Gourgou S, Gianni L, Mollevi C (2015) Clinical development strategies and outcomes in first-in-human trials of monoclonal antibodies. J Clin Oncol Off J Am Soc Clin Oncol 33: 2158-2165.

Trachtman H, Fervenza FC, Gipson DS, Heering P, Jayne DRW, Peters H, Rota S, Remuzzi G, Rump LC, Sellin LK, Heaton JPW, Streisand JB, Hard ML, Ledbetter SR, Vincenti F (2011) A phase 1, single-dose study of fresolimumab, an anti-TGF- $\beta$ antibody, in treatment-resistant primary focal segmental glomerulosclerosis. Kidney Int 79: 1236-1243.

Trarbach T, Moehler M, Heinemann V, Köhne C-H, Przyborek M, Schulz C, Sneller V, Gallant G, Kanzler S (2010) Phase II trial of mapatumumab, a fully human agonistic monoclonal antibody that targets and activates the tumour necrosis factor apoptosis-inducing ligand receptor-1 (TRAIL-R1), in patients with refractory colorectal cancer. $\mathrm{Br} J$ Cancer 102: 506-512.

Van Oers MH, Kuliczkowski K, Smolej L, Petrini M, Offner F, Grosicki S, Levin MD, Gupta I, Phillips J, Williams V, Manson S, Lisby S, Geisler C. PROLONG study investigators (2015) Ofatumumab maintenance versus observation in relapsed chronic lymphocytic leukaemia (PROLONG): an open-label, multicentre, randomised phase 3 study. Lancet Oncol 16: 1370-1379.

Vanhoefer U (2003) Phase I study of the humanized antiepidermal growth factor receptor monoclonal antibody EMD72000 in patients with advanced solid tumors that express the epidermal growth factor receptor. J Clin Oncol 22: 175-184.

Vey N, Bourhis J-H, Boissel N, Bordessoule D, Prebet T, Charbonnier A, Etienne A, Andre P, Romagne F, Benson D, Dombret H, Olive D (2012) A phase 1 trial of the anti-inhibitory KIR mAb IPH2101 for AML in complete remission. Blood 120: 4317-4323.

Wakelee HA, Patnaik A, Sikic BI, Mita M, Fox NL, Miceli R, Ullrich SJ, Fisher GA, Tolcher AW (2010) Phase I and pharmacokinetic study of lexatumumab (HGS-ETR2) given every 2 weeks in patients with advanced solid tumors. Ann Oncol 21: 376-381.

Wallace DJ, Stohl W, Furie RA, Lisse JR, McKay JD, Merrill JT, Petri MA, Ginzler EM, Chatham WW, McCune WJ, Fernandez V, Chevrier MR, Zhong ZJ, Freimuth WW (2009) A phase II, randomized, double-blind, placebo-controlled, dose-ranging study of belimumab in patients with active systemic lupus erythematosus. Arthritis Rheum 61: 1168-1178.

Weber IS, D'Angelo SP, Minor D, Hodi FS, Gutzmer R, Neyns B, Hoeller C, Khushalani NI, Miller WH, Lao CD, Linette GP, Thomas L, Lorigan P, 
Grossmann KF, Hassel JC, Maio M, Sznol M, Ascierto PA, Mohr P, Chmielowski B, Bryce A, Svane IM, Grob JJ, Krackhardt AM, Horak C, Lambert A, Yang AS, Larkin J (2015) Nivolumab versus chemotherapy in patients with advanced melanoma who progressed after anti-CTLA-4 treatment (CheckMate 037): a randomised, controlled, open-label, phase 3 trial. Lancet Oncol 16: 375-384.

Wen PY, Schiff D, Cloughesy TF, Raizer JJ, Laterra J, Smitt M, Wolf M, Oliner KS, Anderson A, Zhu M, Loh E, Reardon DA (2011) A phase II study evaluating the efficacy and safety of AMG 102 (rilotumumab) in patients with recurrent glioblastoma. Neuro-Oncol 13: 437-446.

Wierda WG, Kipps TJ, Mayer J, Stilgenbauer S, Williams CD, Hellmann A, Robak T, Furman RR, Hillmen P, Trneny M, Dyer MJS, Padmanabhan S, Piotrowska M, Kozak T, Chan G, Davis R, Losic N, Wilms J, Russell CA, Osterborg A (2010) Ofatumumab as single-agent CD20 immunotherapy in fludarabine-refractory chronic lymphocytic leukemia. J Clin Oncol 28: 1749-1755.

Wierzbicki R, Jonker DJ, Moore MJ, Berry SR, Loehrer PJ, Youssoufian H, Rowinsky EK (2011) A phase II, multicenter study of cetuximab monotherapy in patients with refractory, metastatic colorectal carcinoma with absent epidermal growth factor receptor immunostaining. Invest New Drugs 29: 167-174.
Yamamoto K, Utsunomiya A, Tobinai K, Tsukasaki K, Uike N, Uozumi K, Yamaguchi K, Yamada Y, Hanada S, Tamura K, Nakamura S, Inagaki H, Ohshima K, Kiyoi H, Ishida T, Matsushima K, Akinaga S, Ogura M, Tomonaga M, Ueda R (2010) Phase I study of KW-0761, a defucosylated humanized anti-CCR4 antibody, in relapsed patients with adult T-cell leukemia-lymphoma and peripheral T-cell lymphoma. J Clin Oncol 28: 1591-1598.

Zhu AX, Finn RS, Mulcahy M, Gurtler J, Sun W, Schwartz JD, Dalal RP, Joshi A, Hozak RR, Xu Y, Ancukiewicz M, Jain RK, Nugent FW, Duda DG, Stuart K (2013) A phase II and biomarker study of ramucirumab, a human monoclonal antibody targeting the VEGF receptor-2, as first-line monotherapy in patients with advanced hepatocellular cancer. Clin Cancer Res 19: 6614-6623.

This work is published under the standard license to publish agreement. After 12 months the work will become freely available and the license terms will switch to a Creative Commons AttributionNonCommercial-Share Alike 4.0 Unported License.

Supplementary Information accompanies this paper on British Journal of Cancer website (http://www.nature.com/bjc) 